\title{
Experimental study on the hydrodynamic impact of tsunami-like waves against impervious free-standing buildings
}

\author{
Davide Wüthrich (D) ${ }^{a}$, Michael Pfister ${ }^{b}$, loan Nistor (D) ${ }^{c}$ and Anton J. Schleiss (D) ${ }^{a}$ \\ aLaboratory of Hydraulic Constructions (LCH), Ecole Polytechnique Fédérale de Lausanne (EPFL), ENAC, Lausanne, Switzerland; ${ }^{\mathrm{b} C i v i l}$ \\ Engineering Department, Haute Ecole d'Ingénierie et d'Architecture de Fribourg (HEIA-FR, HES-SO), Fribourg, Switzerland; 'Department \\ of Civil Engineering, University of Ottawa, Ottawa, Canada
}

ABSTRACT

Tsunamis, landslide-generated waves, and dam failures are rare, but highly destructive phenomena, associated with extreme loading on infrastructure. Recent events showed that specific measures must be taken to guarantee safety of both people and the built environment. This experimental study investigates the forces and moments exerted on free-standing buildings that are induced by both surges and bores. The hydrodynamic impact was characterized by high splash, subsequently followed by a quasi-steady flow around the structure. For dry bed surges, the time history of the horizontal force was proportional to the momentum flux per unit width. For wet bed bores, an attenuation of the peak force due to the presence of an aerated front was observed and the introduction of a reduction coefficient was necessary to achieve a realistic force estimation. Additional force analysis in terms of peak time, wave height at maximum force and impulse also pointed out some key differences between forces exerted by dry bed surges and wet bed bores. The occurrence of the maximum tilting moment on the building coincided with the maximum horizontal force and an evaluation of the cantilever arm was possible. These findings provide engineers with practical information for the design of safer coastal structures.
ARTICLE HISTORY

Received 24 November 2017 Accepted 5 April 2018

KEYWORDS

Tsunami loading; impact forces; impervious free-standing structures; vertical shelters; tilting moment

\section{Introduction}

Extreme natural events such as tsunamis, impulse waves, floods, and storm surges are exposing human communities to severe hazardous consequences. For this reason, protection measures are necessary to reduce negative consequences on the built environment and to limit human losses. Events that took place along the western and northern coasts of Sumatra Island (Indonesia, 2004), central coast of Chile (2010), and in Tōhoku, Japan (2011), showed that specific design features of infrastructures can help save lives. Some 500 people successfully sought refuge at three specifically designed buildings in Ishinomaki, Japan (2011), proving thus that vertical shelters are essential in tsunami-prone coastal areas where access to higher elevation is limited or distant (ASCE 7-2016, Chapter 6). Such situations showed that engineering and coastal planning measures can be effective to ensure safety and reduce reconstruction costs. Research has been focusing in recent years to develop and design infrastructure capable to withstand, within certain limits, the impact and effects of natural disasters and to protect human lives.

Buildings are frequently designed to resist extraordinary lateral forces induced by seismic action or strong winds; however, these are rarely designed to withstand hydrostatic or hydrodynamic loads. The purpose of current tsunami-related studies is to quantify the horizontal loading due to wave-induced impacts on buildings located near the shoreline and combine it with the already existing seismic design guidelines. Nevertheless, some basic differences in building failure modes due to seismic loads, associated with high-frequency dynamic effects and tsunami loads, have been identified and discussed (Nistor et al., 2009). Tsunami waves and associated inland inundation have long periods and are highly transitory. As such, they generate sustained forces whose magnitudes depend on the inundation depth and the flow velocity (ASCE, 2016).

Chanson (2006) showed a strong similarity between tsunami-induced bores and hydrodynamic waves produced by the sudden collapse of a dam. These are best described by the analytical solutions of Ritter (1892) and Stocker (1957) for dry and wet bed scenarios, respectively. Several experimental studies were conducted to investigate the impact of dambreak waves on buildings, most of which were represented by a vertical wall placed across the entire channel width. Worth mentioning are the contributions of Cross (1967), Ramsden (1996), Linton et al. (2012), Mizutani and Imamura (2001), Santo and 
Robertson (2010), and Robertson et al. (2011) and (2013). The interaction between a tsunami-like bore and a $3 \mathrm{D}$ structure is a more complex phenomenon investigated by Arnason, Petroff, and Yeh (2009), Lukkunaprasi et al. (2009), Fujima et al. (2009), Santo and Robertson (2010), Nouri et al. (2010), Al-Faesly et al. (2012), Chinnarasri et al. (2013), Shafiei, Melville, and Shamseldin (2016), and most recently Foster, Rossetto, and Allsop (2017). Yeh (2007) showed that the maximum force is proportional to momentum flux per unit width $\left(h v^{2}\right)$, and Bullock et al. (2007) found a linear relationship between momentum flux and the total impulse for broken, oscillatory waves. A summary of major previous studies focusing on impact forces against free-standing buildings is presented in Table 1.

Despite the work performed to date, the number of empirical or semi-empirical formulas available and their significant scattering suggest that the behavior of structures under such extreme loading remains challenging to describe and quantify (Section 5.4). Furthermore, most studies focused on values of the blockage ratio $\beta \approx 1$ (Table 1 ), where $\beta$ is defined as the ratio between channel width $W$ and obstacle size $B$. The effect of blockage ratio was investigated by Qi, Eames, and Johnson (2014) for free-surface channel flows with constant discharge and by Foster, Rossetto, and Allsop (2017) for unsteady flows.

Guidelines were presented by $\mathrm{CCH}$ (2000) and FEMA55 (2000). In Japan, the current design guideline is represented by SMBTR, based on the results of Asakura et al. (2000). Okada et al. (2005), and Tokyo University and BRI (2011). Most recently, the 2016 edition of the ASCE-7 standard entitled "Minimum design loads for buildings and other structures" introduced a specific Chapter 6, "Tsunami loads and effects" (ASCE 7-06; Chock, 2016; Robertson, 2016). The latter identified tsunami building categories depending on their importance. The present study focuses on buildings belonging to Tsunami Risk Category II, i.e. structures acting as vertical shelters with an elevation higher than $19.8 \mathrm{~m}$ at prototype level. Some of the major formulae found in literature to compute waveinduced loads are presented in Table 2.

Wüthrich et al. (2018) carried out a recent study focusing on the wave hydrodynamics properties of bores and surges generated using the vertical release of a controlled volume of water. These findings in terms of velocity profiles and momentum flux are used herein to quantify the hydrodynamic loads induced by the generated surges and bores onto a free-standing building. During the tsunami inflow, the horizontal force $F_{\mathrm{x}}$ is dominant in magnitude and its estimation is essential to properly design buildings identified as tsunami vertical shelters. The loading mechanism onto a free-standing structure was experimentally measured, providing helpful information on the magnitude of the wave-induced forces and its application point. Compared to previous studies, this paper directly applies the recent results by Wüthrich et al. (2018) in terms of velocity profiles behind the wave front and momentum flux for the computation of the resulting hydrodynamic load conditions. In addition, detailed analysis techniques are presented herein, including the impulse transferred from the wave to the building, the wave height at which the maximum takes place, and the moment generated by the force and its application point (cantilever arm).

\section{Experimental set-up}

\subsection{Wave generation}

The present study is based on an experimental approach and all tests were carried out at the Laboratory of Hydraulic Constructions at Ecole Polytechnique Fédérale de Lausanne (EPFL) in Switzerland. Both dry bed surges and wet bed bores were generated using a vertical release technique, as previously presented by Wüthrich et al. (2018). Similar generation techniques were used by Chanson, Aoki, and Maruyama (2002), Rossetto et al. (2011), and Meile, Boillat, and Schleiss (2011). The scaling of this experimental program considered the Froude similitude with a geometrical scale ratio 1:30, and the experimental set-up is presented in Figure 1. An upper reservoir with a volume of $7 \mathrm{~m}^{3}$ was connected to a water-filled lower reservoir through three identical and independent pipes with an internal diameter of $315 \mathrm{~mm}$. Each pipe was fitted with a valve, and the sudden water release was performed through a system of pulleys and inextensible ropes. When the release system was activated, resulting in a sudden difference in total head, the water from the upper reservoir started flowing into the lower tank and further into the horizontal channel with a width $W$ of $1.4 \mathrm{~m}$, a height of $0.9 \mathrm{~m}$, and a length of $15.5 \mathrm{~m}$. Through steady-state experiments under various flow conditions, the Darcy-Weisbach friction factor of the channel was determined to be 0.021 , corresponding to a roughness of $0.66 \mathrm{~mm}$. The water was evacuated at the downstream end of the channel through a vertical drain, avoiding thus any backwater effect. For the generation of wet bed bores, an initial still water depth $\left(h_{0}\right)$ on the flume ("wet bed" condition) was ensured by using a vertically adjustable sill located at the downstream end of the channel (Figure 1).

The characteristics of the dry bed surges and wet bed bores generated in the present study were demonstrated to be similar to those of the classical dam-break waves and were also verified against the analytical solutions of Ritter (1892) and Stocker (1957), respectively (Wüthrich et al., 2018). Unlike the use of 


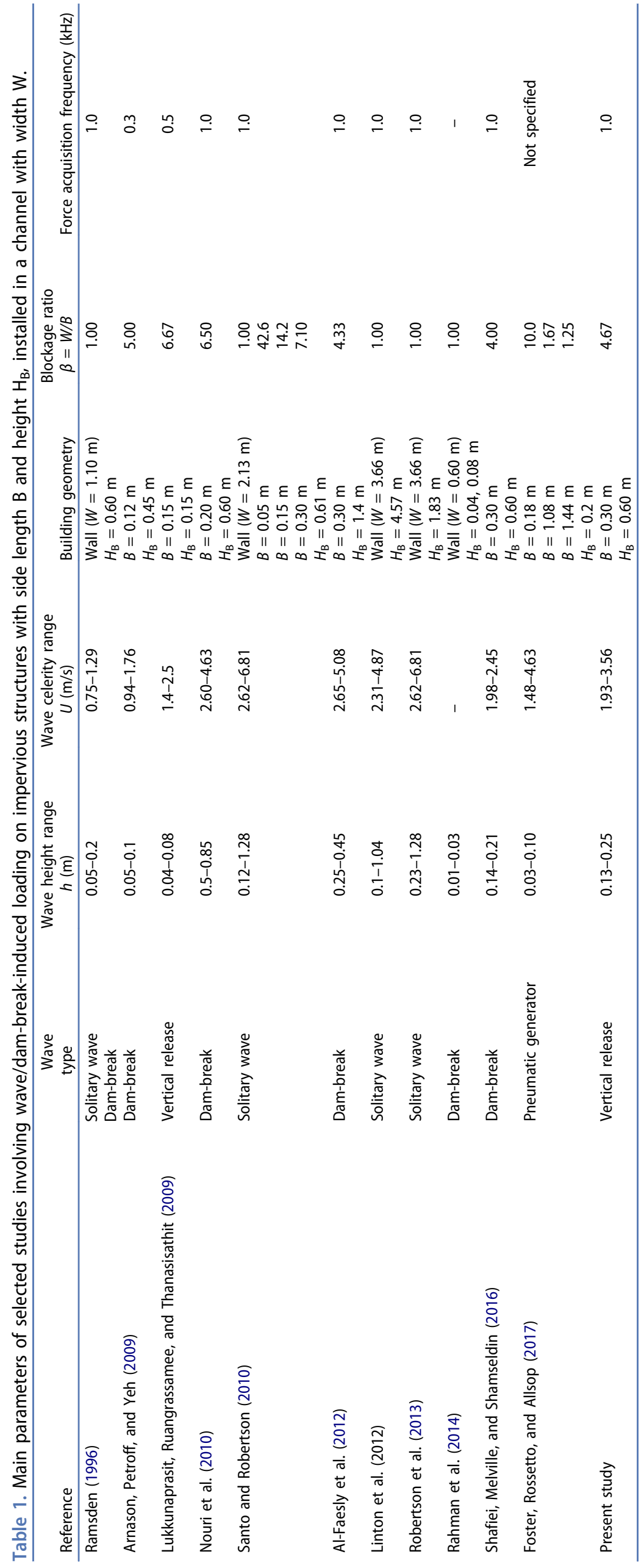


Table 2. Summary of major formulae in literature to predict wave-induced forces on structures.

\begin{tabular}{|c|c|c|}
\hline Study & Formula & Note \\
\hline Cross (1967) & $F_{\mathrm{x}, \mathrm{D}}=\frac{1}{2} \rho g B h_{2}^{2}+\rho B h_{2} U^{2}$ & $\begin{array}{l}\text { Force is given by the sum of hydrostatic and hydrodynamic } \\
\text { components. }\end{array}$ \\
\hline $\begin{array}{l}\text { Japanese design guideline } \\
\text { (SMBTR) }\end{array}$ & $F_{\mathrm{x}, \mathrm{D}}=\frac{1}{2} \rho g B\left[3\left(h_{2}-h_{0}\right)\right]^{2}$ & $\begin{array}{l}\text { Equation based on Asakura et al. (2000) and Okada et al. (2005). } \\
\text { This generates a force equals to nine times the hydrostatic force } \\
\text { magnitude. Yeh, Robertson, and Preuss (2005) commented on } \\
\text { the validity of this equation, indicating that this leads } \\
\text { "excessively overestimated values." }\end{array}$ \\
\hline Fujima et al. (2009) & $F_{\mathrm{x}, \mathrm{D}}=1.3 \rho B\left(h_{2}-h_{0}\right) U^{2}$ & $\begin{array}{l}\text { Similar to Asakura et al. (2000), but based on the maximum } \\
\text { inundation depth. }\end{array}$ \\
\hline $\begin{array}{l}\text { OCADI, } 2009 \text { (Overseas } \\
\text { Coastal Area } \\
\text { Development Institute) }\end{array}$ & $F_{\mathrm{x}, \mathrm{D}}=3.3 \rho g B\left(h_{2}-h_{0}\right)^{2}+2.2 \rho g B\left(h_{2}-h_{0}\right) \cdot h_{0}$ & $\begin{array}{l}\text { Triangular pressure distribution above the still water level with } \\
\text { height } 3 h \text { and base pressure given by } 2.2 \rho g h \text {. This base pressure } \\
\text { is maintained constant throughout the depth of still water } h_{0} \text {. }\end{array}$ \\
\hline ASCE7 Chapter 6 & $\begin{array}{l}F_{x, D}=\left.0.933 k_{s} \rho g\right|_{\mathrm{tsu}} B h_{\max }^{2} \\
F_{x, D}=1.6 \cdot k_{s} \rho g I_{\mathrm{tsu}} B h_{\max }^{2}\end{array}$ & $\begin{array}{l}\text { Hydrodynamic formula } 6.10-1 \text {. } \\
\text { More conservative approach than } 6.10-1 \text {. }\end{array}$ \\
\hline Robertson et al. (2013) & $F_{\mathrm{x}, \mathrm{D}}=\rho B\left\{\frac{1}{2} g h_{2}^{2}+\left(h_{2}-h_{0}\right) U^{2}+g^{\frac{1}{3}} \cdot\left[\left(h_{2}-h_{0}\right) U\right]^{\frac{4}{3}}\right\}$ & $\begin{array}{l}\text { This equation was successfully proved during the } 2011 \text { Japan } \\
\text { tsunami by Chock et al. (2012). }\end{array}$ \\
\hline $\begin{array}{l}\text { Foster, Rossetto, and } \\
\text { Allsop (2017) }\end{array}$ & $F_{\mathrm{x}, \mathrm{D}}=\lambda B g^{\frac{1}{3}}\left(U h_{\max }\right)^{\frac{4}{3}}$ & $\begin{array}{l}\text { For unsteady flow regime: } \\
\lambda=1.37-1.35\left(\frac{B}{W}\right)+1.37\left(\frac{B}{W}\right)^{2}\end{array}$ \\
\hline
\end{tabular}

solitary waves, dam-break waves are considered a more appropriate technique to reproduce the properties of tsunami-like bores and surges propagating inland (Yeh, Liu, and Synolakis, 1996; Chanson, 2006; Madsen, Fuhrman, and Schäffer, 2008; Nistor et al., 2009; Nouri et al., 2010). The triggering of the release mechanism resulted in a relatively constant discharge into the channel, and a quasi-constant water level was observed in the channel inlet (US1) for a duration ranging from 8 to $20 \mathrm{~s}$ depending on the initial release discharge. As explained by Wüthrich et al. (2018), this allowed to compute an equivalent impoundment water depth $d_{0}$, providing thus a meaningful comparison with the classical dam-break scenarios (Figure 1, Table 2).

\subsection{Building models}

The tested buildings were located at a distance $x=14.00 \mathrm{~m}$ from the channel inlet to ensure the full development of the bores/surges. One single building model was tested in the present study, as shown in Figure 2, with dimensions $B \times B \times$ $H_{\mathrm{B}}=0.3 \mathrm{~m} \times 0.3 \mathrm{~m} \times 0.6 \mathrm{~m}$. This resulted in $\mathrm{a}$ blockage ratio $\beta=W / B=4.67$ which was sufficiently large to limit side wall effects and was consistent with previous studies (Table 1). The impermeable building had a square shape, and it was made of aluminum plates with a uniform thickness of $0.01 \mathrm{~m}$. This was designed to be completely rigid, ensuring that the structure's dynamic response could be neglected. Some FEM numerical simulations of push-over tests allowed to calculate a stiffness values around $2 \cdot 10^{8} \mathrm{~N} / \mathrm{m}$ for all buildings. These buildings corresponded to prototype structures of $9 \mathrm{~m}$ if a geometrical scale of 1:30 is assumed. Such dimensions would be typical for residential buildings commonly observed in coastal zones exposed to tsunami hazard. The building height $H_{\mathrm{B}}=0.6 \mathrm{~m}$ (Figure 1) was representative of a vertical shelter belonging to the Tsunami Risk Category II, as defined by ASCE-7 Chapter 6 .

The eigenfrequencies of the buildings were estimated through Fast Fourier Transformation of a hammer-induced horizontal force, $F_{\mathrm{x}}$. For this configuration, a value of $31.6 \mathrm{~Hz}$ was obtained in $x$-axis direction. This value is within the same range as that identified by Arnason, Petroff, and Yeh (2009) and Nouri et al. (2010) for similar buildings. It is important to point out that the eigenfrequencies of the investigated structures were sufficiently high to avoid any interference with the flow frequency $f \sim 1.0-1.5 \mathrm{~Hz}$, obtained for a Strouhal number St $=f \cdot B / U=0.15$, where $B$ is the building width and $U$ the wave front celerity.

\subsection{Instrumentation and measuring technique}

The profiles of the propagating waves and the runup heights produced during the impact on the building were investigated using seven Ultrasonic distance Sensors (US) type Baumer UNAM 3016103, with a measuring range of the flow depth between 0.1 to $1 \mathrm{~m}$. Water levels were sampled with an accuracy of $0.5 \mathrm{~mm}$ and an instrument response time of less than $80 \mathrm{~ms}$. The location of these instruments is shown in Figure 1. Among these, five sensors were located along the longitudinal axis of the channel at $x=2.00,10.10,12.10,13.35$, and $13.85 \mathrm{~m}$ from the flume inlet, i.e. the downstream edge of the lower basin. One sensor was located on the roof of the building to measure any potential overflow (US6) while another one (US7) was located at the same location as the 


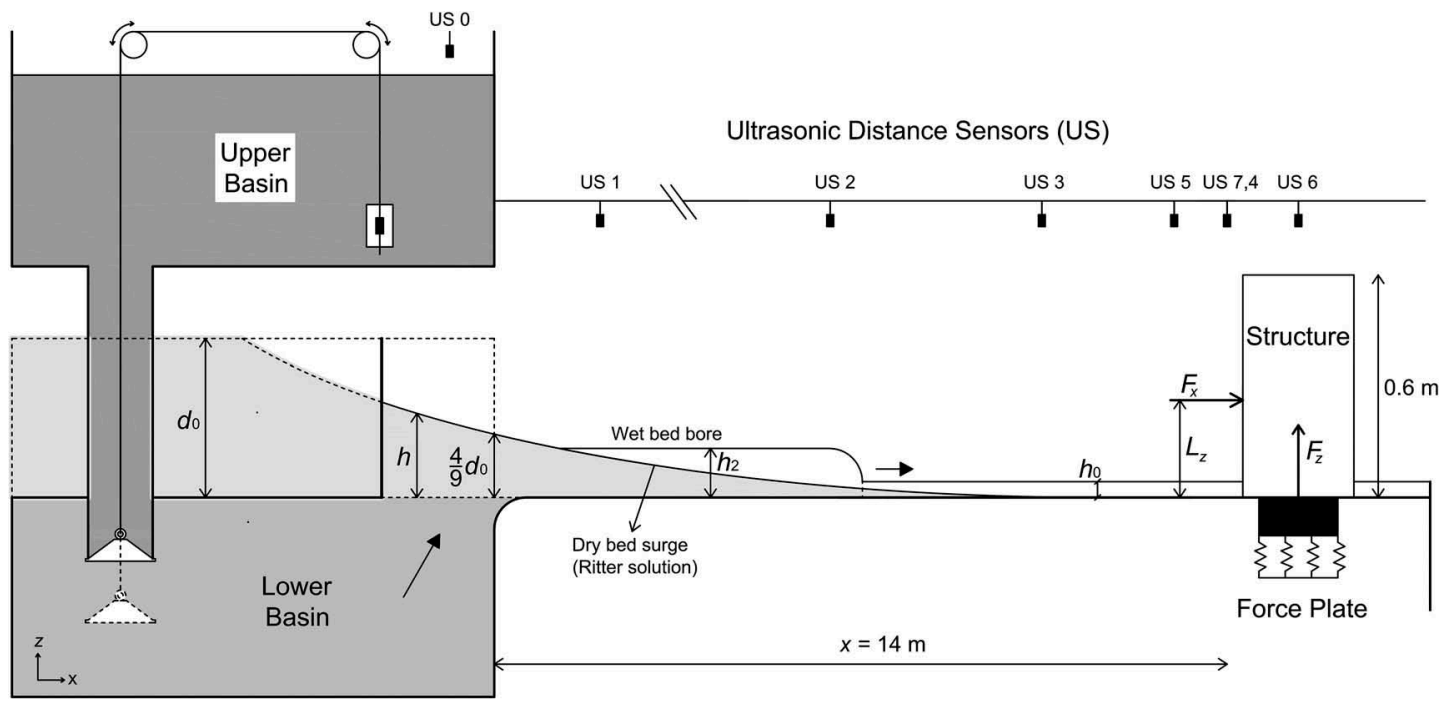

Figure 1. Experimental set-up used to produce bores and surges with the vertical release technique.

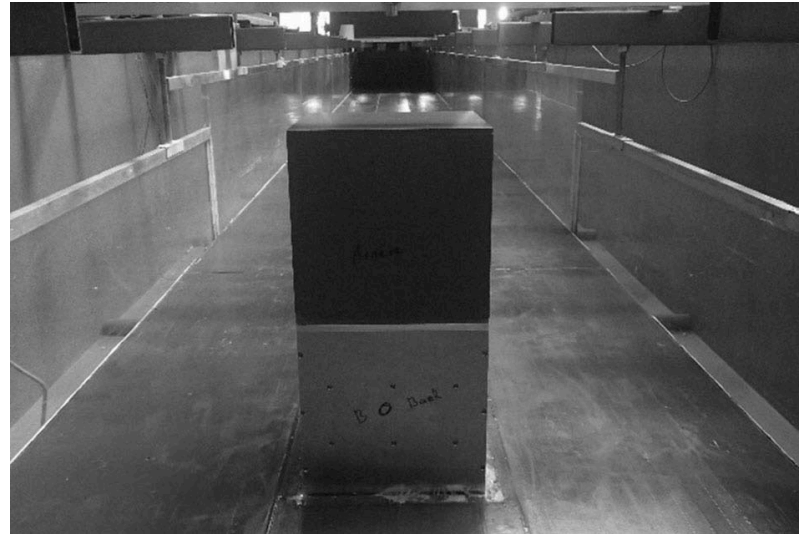

Figure 2. Impervious structural model configuration ( $B=0.3 \mathrm{~m}, H_{\mathrm{B}}=0.6 \mathrm{~m}$ ) used for the present study.

building model at $x=13.85 \mathrm{~m}$ on its left hand side, at $y / B=-0.25$. An additional sensor (USO) with an extended measuring range (UNAM 50, 250-4000 $\mathrm{mm}$ ) was installed in the upper reservoir to ensure the accurate recording of the time history of the water level in the reservoir based on which the opening instant of the system ( $t=0 \mathrm{~s})$ was also defined.
As shown in Figure 1, the buildings were installed on a force plate (AMTI MC6-1000) that recorded the time history of the impact forces and moments, including surge and drag components, with a sampling frequency of $1 \mathrm{kHz}$. For all scenarios, the time histories of the forces and moments in all three dimensions were measured. The coordinate system is shown in Figures 1 and 3. The following sign convention is used throughout the paper: $F_{\mathrm{x}}$ is positive in the flow direction (frontal impact), $F_{\mathrm{y}}$ is positive to the left if surfing the wave downstream the flume, and $F_{z}$ is positive in upward direction.

Calibration parameters for the force device were provided by Prophysics SA on behalf of AMTI. However, in both $x$ - and $y$-directions, force measurements were compared to those provided by a HCB Hanging Scale Device (KERN, Germany) with a precision of $\pm 0.1 \mathrm{~N}$. In addition, preliminary tests were carried out for a passing wave without the presence of the building. The related forces are presented in Figure 4 for a dry bed surge.

The measurements of the force along the $z$-axis were compared to the weight of the water column as the wave passing over the force plate (Eq. (1)).

$$
F_{\mathrm{z}}=h \cdot B^{2} \cdot g \cdot \rho
$$
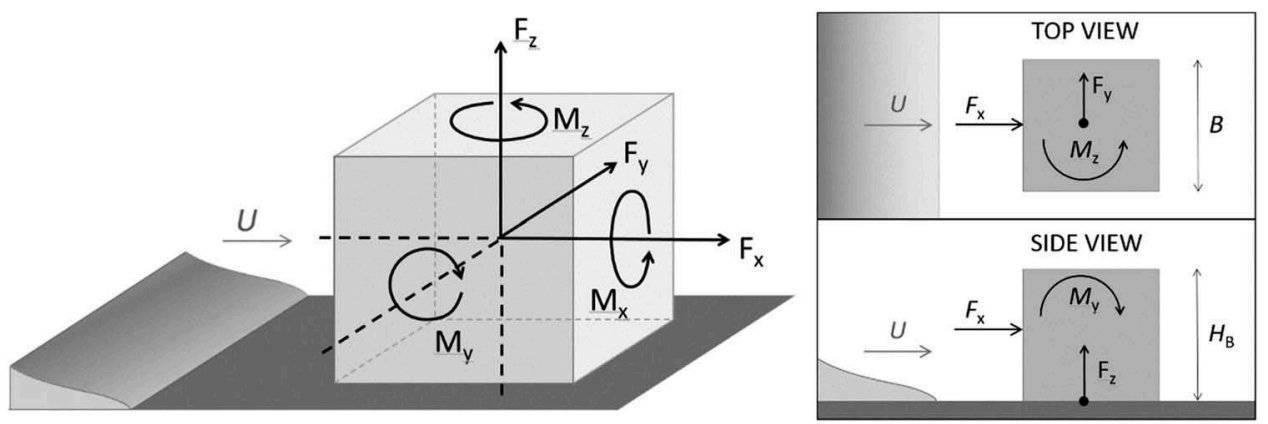

Figure 3. Coordinates system used herein. 

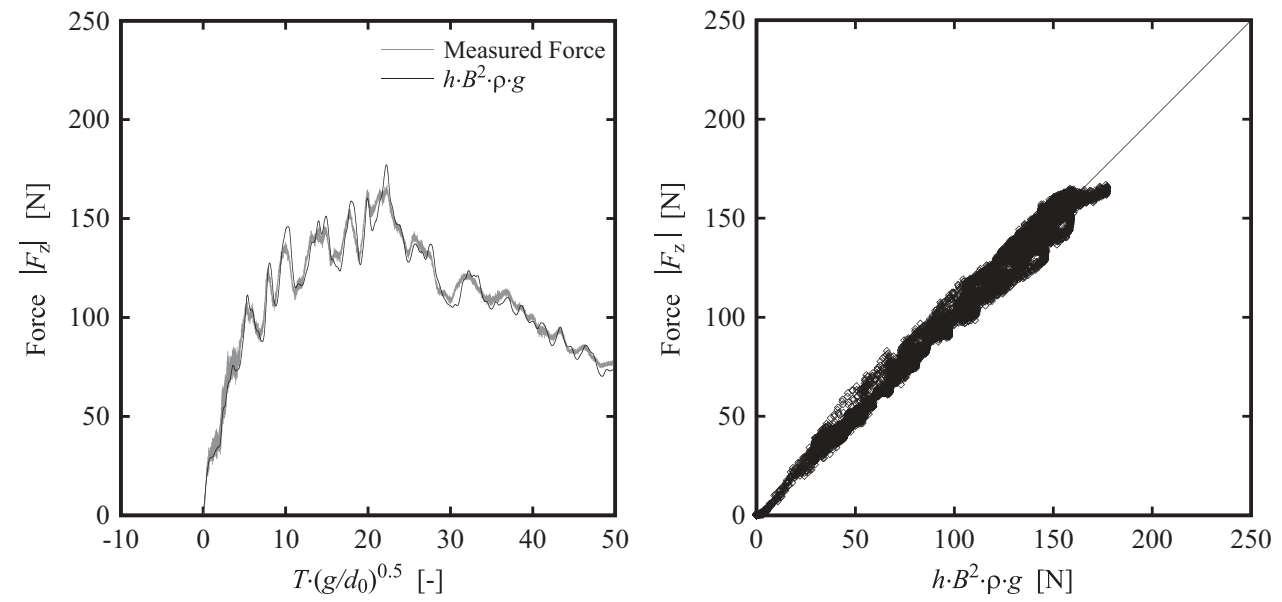

Figure 4. Comparison between measured force $F_{\mathrm{z}}$ and the calculated weight through Eq. (1) $\left(d_{0}=0.82 \mathrm{~m}\right.$, dry bed).

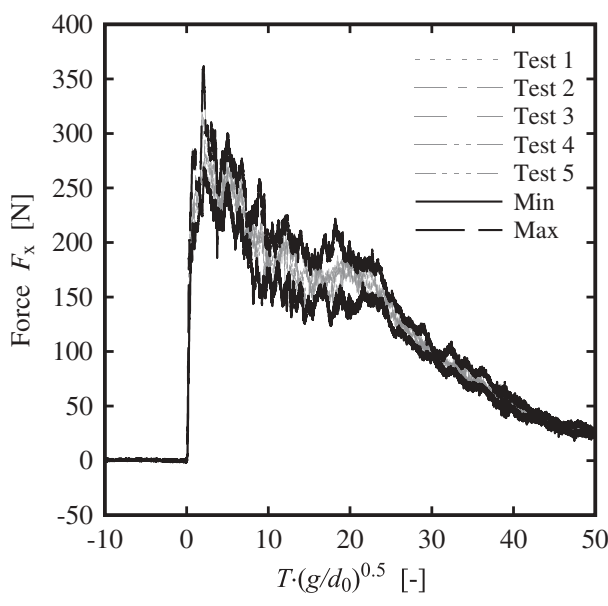

(a)

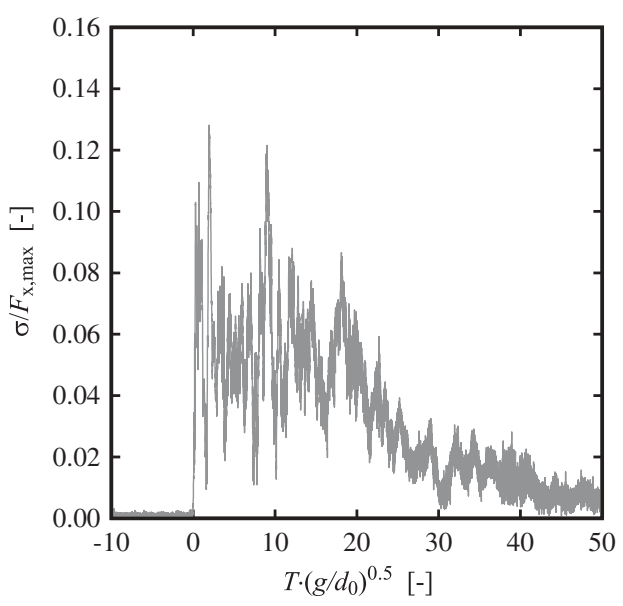

(b)

Figure 5. (a) Repeatability of the time histories of force $F_{\mathrm{x}}$ for a wet bed bore impacting an impervious building $\left(d_{0}=0.82 \mathrm{~m}, h_{0}\right.$ $=0.010 \mathrm{~m}$ ); (b) Standard deviation for a dry bed surge.

Good agreement was observed for $F_{\mathrm{z}}$ for both the dry bed surge and the wet bed bore (not shown). Good repeatability of the force measurements in $x$-direction is shown in Figure 5, with standard deviation below $13 \%$.

\section{Experimental methodology}

A total of 45 tests were carried out for 12 standard waves (equal to test numbers in Table 3 ) with different hydrodynamic properties. The maximum recorded

Table 3. Experimental program.

\begin{tabular}{|c|c|c|c|c|c|c|c|c|c|}
\hline \multirow[b]{2}{*}{ Building } & \multicolumn{6}{|c|}{ Wave } & \multirow[b]{2}{*}{ Repetitions } & \multirow[b]{2}{*}{ Test Number } & \multirow[b]{2}{*}{ Symbol } \\
\hline & $\begin{array}{l}\text { Bed } \\
\text { type }\end{array}$ & $\begin{array}{l}\text { Impoundment depth } \\
d_{0}(\mathrm{~m})\end{array}$ & $\begin{array}{l}\text { Initial water depth } \\
h_{0}(\mathrm{~m})\end{array}$ & $\begin{array}{l}\text { Celerity } \\
U(\mathrm{~m} / \mathrm{s})\end{array}$ & $h_{\max }(\mathrm{m})$ & $\begin{array}{c}h_{0} / h_{\max } \\
(-)\end{array}$ & & & \\
\hline \multirow[t]{12}{*}{$H_{B}=0.6 m$} & Dry & 0.82 & 0 & 3.56 & 0.18 & 0 & 4 & 1 & $\bullet$ \\
\hline & & 0.63 & 0 & 3.11 & 0.16 & 0 & 3 & 2 & $\diamond$ \\
\hline & & 0.40 & 0 & 2.35 & 0.13 & 0 & 4 & 3 & $\diamond$ \\
\hline & Wet & 0.82 & 0.01 & 3.07 & 0.19 & 0.05 & 4 & 4 & - \\
\hline & & & 0.03 & 2.81 & 0.23 & 0.13 & 4 & 5 & $\boldsymbol{\Delta}$ \\
\hline & & & 0.05 & 2.76 & 0.26 & 0.19 & 4 & 6 & $\overrightarrow{0}$ \\
\hline & Wet & 0.63 & 0.01 & 2.70 & 0.17 & 0.06 & 3 & 7 & 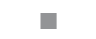 \\
\hline & & & 0.03 & 2.52 & 0.20 & 0.15 & 3 & 8 & $\bar{\Delta}$ \\
\hline & & & 0.05 & 2.44 & 0.22 & 0.22 & 3 & 9 & $\overline{0}$ \\
\hline & & 0.40 & 0.01 & 2.10 & 0.14 & 0.07 & 5 & 10 & $\square$ \\
\hline & & & 0.03 & 1.97 & 0.16 & 0.18 & 4 & 11 & $\triangle$ \\
\hline & & & 0.05 & 1.93 & 0.18 & 0.28 & 4 & 12 & $\overline{0}$ \\
\hline Min & & 0.40 & 0 & 1.93 & 0.13 & 0 & 3 & - & - \\
\hline Max & & 0.82 & 0.05 & 3.56 & 0.26 & 0.28 & 5 & - & - \\
\hline
\end{tabular}


wave height $h_{\max }$ was $0.18 \mathrm{~m}$ for the dry bed surge and $0.26 \mathrm{~m}$ for the wet bed bore, with a front celerity $U$ ranging from 1.93 to $3.55 \mathrm{~m} / \mathrm{s}$. All parameters concerning the wave without the presence of the buildings were obtained as average values of minimum three tests. For a scaling of 1:30, these values corresponded to a prototype wave height of 5.5-8 $\mathrm{m}$ and a prototype celerity of $10.7-19.4 \mathrm{~m} / \mathrm{s}$, values which are consistent with reported field observations during the 2011 Tohoku Tsunami (Chock et al., 2012; Fritz et al., 2012; Jaffe et al., 2012).

\section{Visual observations}

\subsection{Surges and bores}

As pointed out by various authors, waves propagating on dry or wet bed have different physical characteristics (Ramsden, 1996; Chanson, 2004; Nouri et al., 2010; Wüthrich et al., 2018), Such difference in behavior between a dry bed surge and a wet bed bore can be observed in Figure 6. Dry bed surges are characterized by a non-aerated front followed by a constant increase in flow depth, whereas bores present a strongly turbulent aerated roller front which propagates along the channel and which is associated with a sudden rise in flow depth, followed by a relatively constant level $h_{2}$ (Figure 1). Furthermore, surges presented higher front velocities, whereas bores had greater wave heights. A dry bed surge is representative of the first incoming tsunami-induced inundation, whereas a wet bed bore may represent any following inundation wave. Both scenarios have to be equally considered since past tsunami inundation events showed that the maximum resulting force may not always be associated with the first incoming waveinduced inundation.

\subsection{Wave impact process}

Visual observations proved that the difference between surges and bores discussed in Section 4.1 resulted into slightly different behaviors during the wave impact with an impervious free-standing building. For both cases, two main phases were observed: (1) an initial impact of the wave front, followed by (2) a quasi-steady hydrodynamic phase. Both phases are shown in Figure 7, where the time evolution of the impact is presented through pictures taken for both surges and bores at $T \cdot\left(g / d_{0}\right) \cdot{ }^{0.5} \approx 0$ (impact phase, with highest run-up) and $T \cdot\left(g / d_{0}\right)^{0.5} \approx 14$ and 28 (postimpact hydrodynamic phase). Note that in the chosen normalization $T$ represents the time, $g$ the gravity constant, and $d_{0}$ the equivalent impoundment depth if a dam-break theory is considered (Wüthrich et al. (2018)). Similar qualitative results were previously presented by Wüthrich, Pfister, and Schleiss (2016) for the case of buildings toppled by overflow.

During the initial impact phase, the wave front hit the building's upstream side and a vertical run-up height $H$ was observed. As shown in Figure 7(a-d), for both the cases of bores and surges, the impact phase was characterized by significant splashes and turbulent air entrainment at the upstream side of the building. Subsequently, the run-up and splashes fell onto the incoming wave, producing a stationary roller on the upstream side. This roller is characterized by high turbulence, a recirculating pattern, and substantial air entrainment. The formation of a roller in the upstream side is shown in Figure $7(\mathrm{e}, \mathrm{f})$, and it marked the transition between the impact phase and the quasi-steady hydrodynamic one. During this phase, the main body of the wave continuously flowed around the building, without major changes in flow behavior. In addition, constant water depths on both the upstream and the downstream sides were observed, until these decreased after the passage of the wave. The duration of the quasi-steady flow ranged between $20<t \cdot\left(g / d_{0}\right)^{0.5}<70$, depending on the hydrodynamic properties of the wave. As shown in Figure $7(\mathrm{e}-\mathrm{g})$ and $(\mathrm{f}-\mathrm{h})$, a visual assessment indicated that dry bed surges presented higher air entrainment compared to wet bed bores. Dry bed surges were also characterized by a pulsating flow behavior, which is

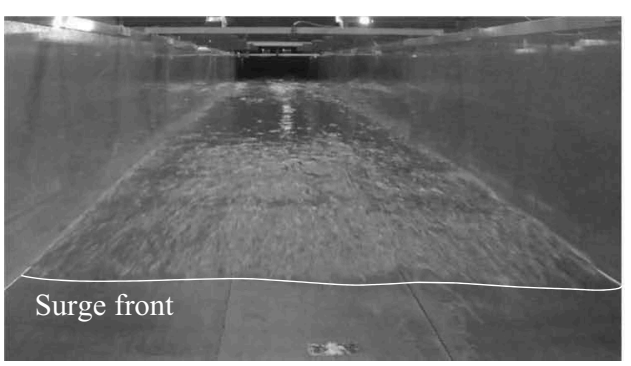

(a)

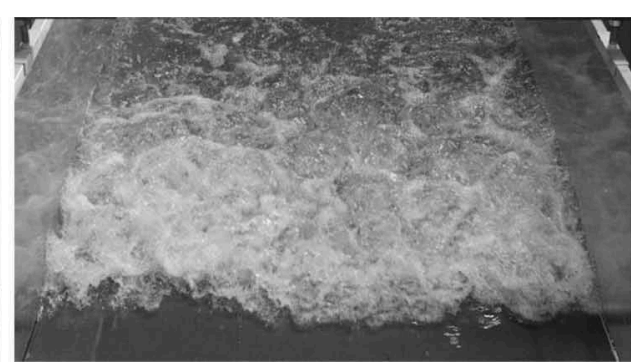

(b)

Figure 6. Photos of propagating waves: (a) dry bed surge $\left(d_{0}=0.63 \mathrm{~m}, h_{\max }=0.162 \mathrm{~m}, U=3.11 \mathrm{~m} / \mathrm{s}\right)$ and (b) wet bed bore $\left(d_{0}=0.63 \mathrm{~m}, h_{0}=0.03 \mathrm{~m}, h_{\max }=0.201 \mathrm{~m}, U=2.52 \mathrm{~m} / \mathrm{s}\right)$. (Images by D. Wüthrich) 


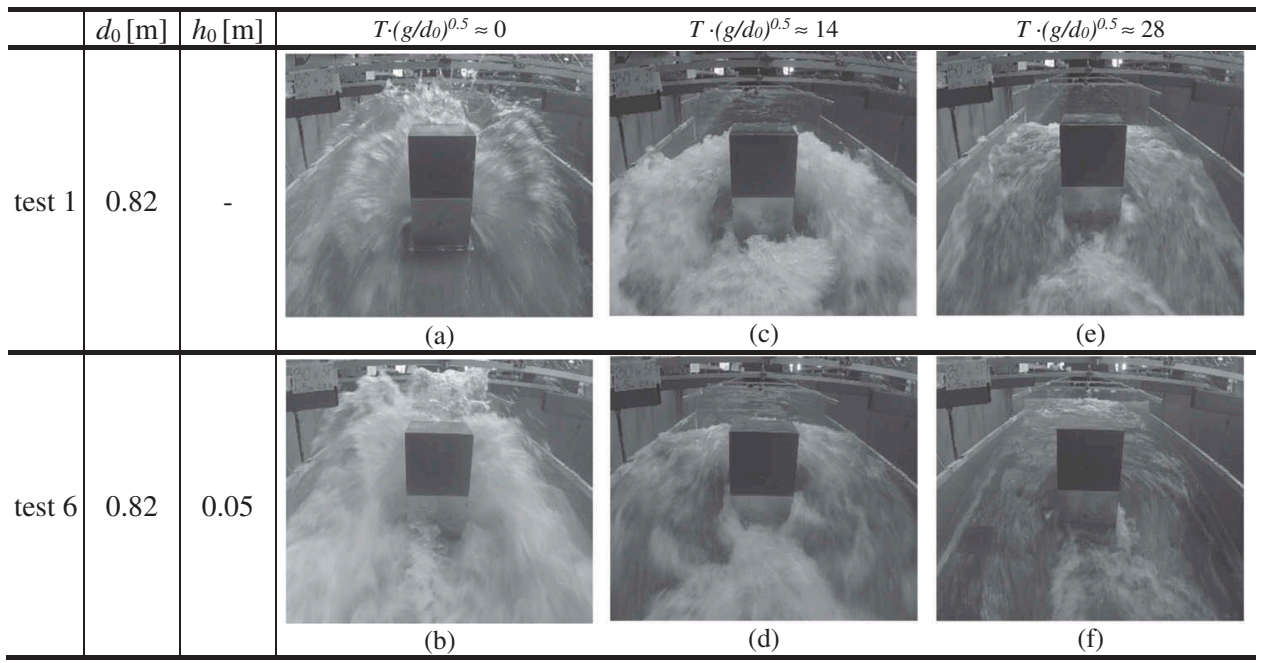

Figure 7. Wave impact against an impervious buildings without overflow: (top) dry bed surge: $d_{0}=0.82 \mathrm{~m}$, test 1; (bottom) wet bed bore: $d_{0}=0.82 \mathrm{~m}, h_{0}=0.05 \mathrm{~m}$, test 6 . (Images by D. Wüthrich)

attributed to the interaction between the high-speed incoming wave and the return motion of the vertical run-up. For all test cases, no overflow of the building was seen. For all configurations, intense von Kármán vortices in the downstream side of the building were observed (Figure 7).

The Ultrasonic Sensor US7, located $0.15 \mathrm{~m}$ upstream of the building (Figure 1), measured the time history of the vertical run-up heights $H$, providing a more quantitative description of the previously discussed visual observations. The results are shown in Figure 8 for both a dry bed surge and a wet bed bore. These are compared with the wave profile $h$ measured without the building. Results showed similar maximum values $H_{\max }$ corresponding to approximately four times the maximum wave height without

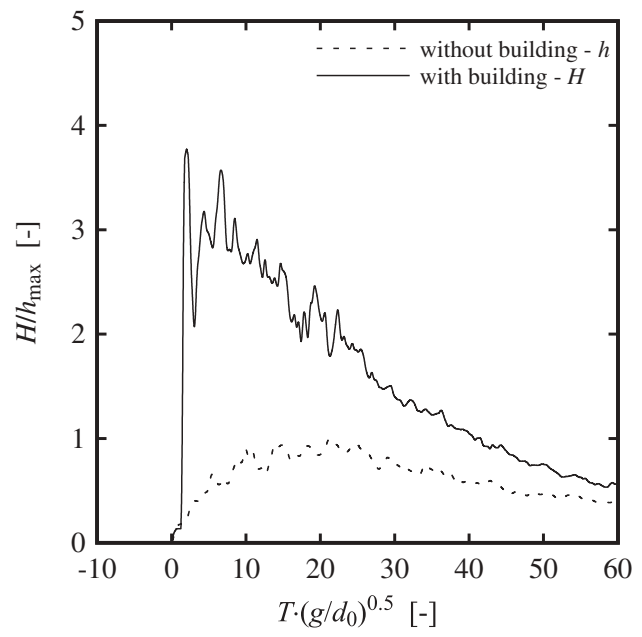

(a) the building $h_{\max }$. If compared to bores, the measurements for the dry bed surge showed a more fluctuating behavior and a constant decrease. On the contrary, wet bed bores showed a sudden reduction in water depth immediately following the run-up splash provoked by the initial impact.

\section{Impact forces}

An example of the raw data recorded for forces and moments measured at the building induced by a dry bed surge and a wet bed bore is presented in Figure 9. For the same release conditions $\left(d_{0}=0.63 \mathrm{~m}\right)$, similar force maxima were observed for both the dry bed surge and the wet bed bore. As a consequence of their hydrodynamic behavior

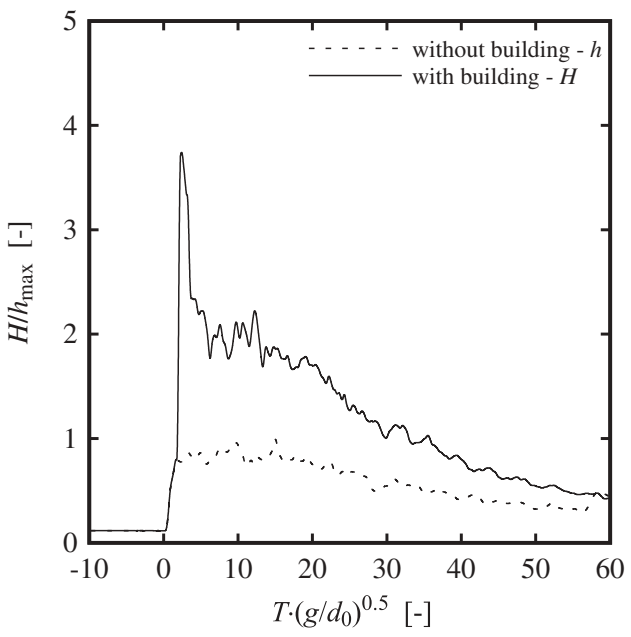

(b)

Figure 8. Vertical run-up heights (measured at US 7) for (a) dry bed surge; (b) wet bed bore with $h_{0}=0.03 \mathrm{~m}$. 

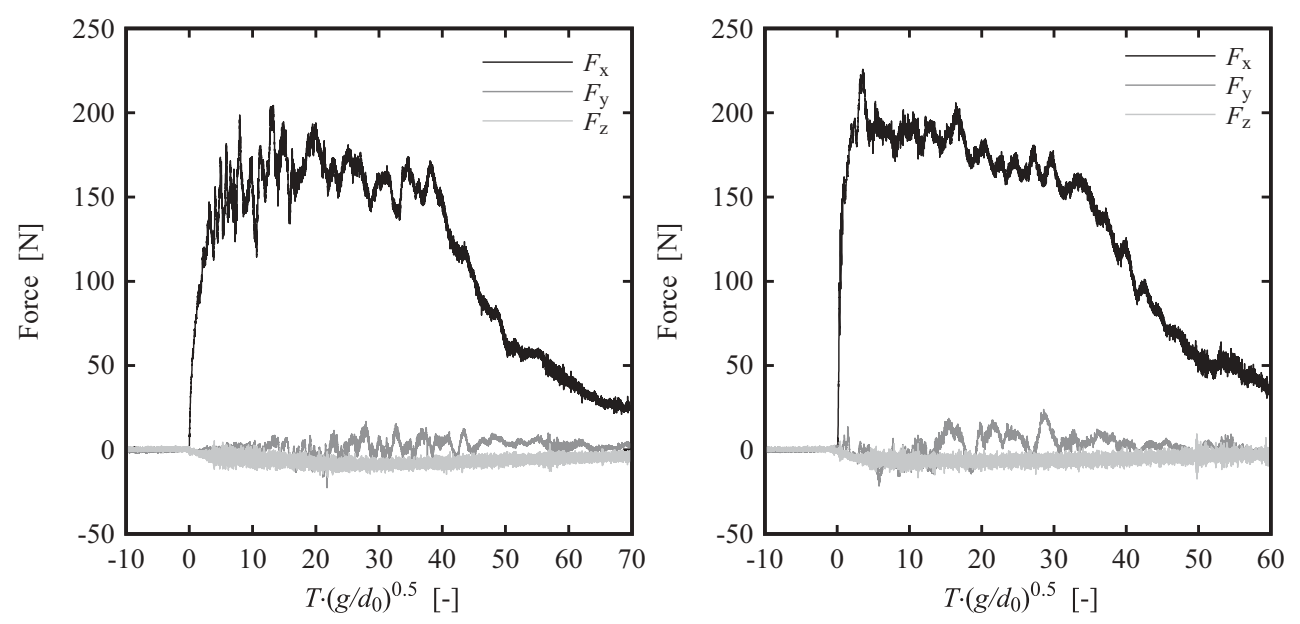

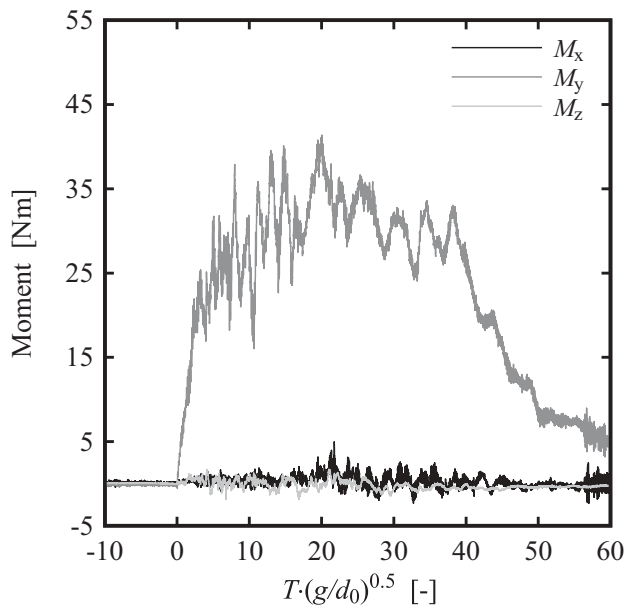

(a)

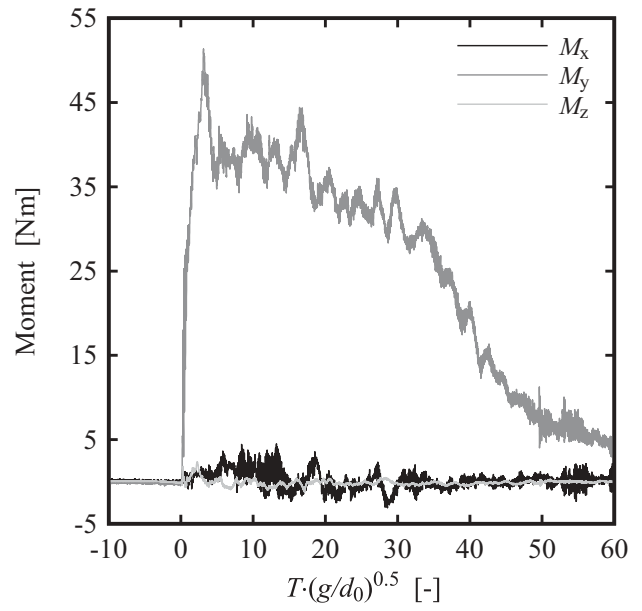

(b)

Figure 9. Time histories of forces and moments in $x$-direction for both the dry bed surge, $d_{0}=0.63 \mathrm{~m}$ (test 2) (a) and wet bed bore, $d_{0}=0.63 \mathrm{~m}, h_{0}=0.03 \mathrm{~m}$ (test 8) (b).

(Section 4.2), wet bed bores generated a sudden rise in the horizontal force $F_{\mathrm{x}}$ and moment $M_{\mathrm{y}}$, whereas dry bed surges were associated with a more gradual rise in time. These behaviors are in agreement with those of Arnason, Petroff, and Yeh (2009) and Nouri et al. (2010). The magnitude of the forces and moments in the transversal $\left(F_{\mathrm{y}}, M_{\mathrm{x}}\right)$ and vertical direction $\left(F_{z}, M_{z}\right)$ was negligible compared to those recorded in the flow direction $\left(F_{\mathrm{x}}, M_{\mathrm{y}}\right)$, proving the bi-dimensionality of the phenomenon. For this reason, the values of $F_{\mathrm{y}}, F_{\mathrm{z}}, M_{\mathrm{x}}$, and $M_{\mathrm{z}}$ are hereafter neglected and not discussed herein. Given the differences between the force time history, the two waves are hereafter considered separately: the dry bed surge is described in Section 5.1 while the wet bed bore is described in Section 5.2.

\subsection{Dry bed surges}

The horizontal force produced by a flow moving against an obstacle can be calculated using the approach proposed by Morison, Johnson, and Schaaf
(1950). These equations take into account the hydrodynamic (or drag) force component and the inertia component. For tsunamis, due to their long periods, the inertia component becomes important only at the leading edge of the incoming wave when the wave impacts the building: this is often termed surge force. The quasi-steady hydrodynamic component in the $x$-direction, $F_{\mathrm{x}, \mathrm{D}}$, can be computed as

$$
F_{\mathrm{x}, \mathrm{D}}=\frac{1}{2} \rho C_{\mathrm{D}} B \cdot\left(h v^{2}\right)=\frac{1}{2} \rho C_{\mathrm{D}} B \cdot M
$$

where $\rho$ is the water density $\left(\rho=1000 \mathrm{~kg} / \mathrm{m}^{3}\right), B$ the building width, $h$ the flow depth (without building), and $v$ the flow velocity. $M$ is the wave momentum flux per unit width that is obtained through a combination of wave height and flow velocity $\left(M=h v^{2}\right)$. The drag coefficient $C_{D}$ depends on the obstacle geometry and the flow conditions. More details regarding the drag coefficient can be found in Blevins (1984).

During these experimental tests, in agreement with what was visually observed after the initial impact, the flow became quasi-steady due to the surge's long period. Therefore, the estimation of the force could 
be obtained through Eq. (2). It is important to point out that the maximum force $F_{\mathrm{x} \text {, max }}$ does not occur when both $h$ and $v$ are maximum, but when the momentum flux per unit width $\left(M=h v^{2}\right)$ is maximum, i.e. $M_{\max }=\left(h v^{2}\right)_{\max } \neq h_{\max } v_{\text {max }}^{2}($ Yeh, Liu, and Synolakis, 1996; Yeh, 2007).

Some data time series for the dry bed surge are presented in Figures 9 and 10, in which one can notice a constant increase of the force until a quasiconstant value is reached, corresponding to the quasisteady hydrodynamic phase. In the present case, no force overshot due to surge component was observed during the initial impact, as discussed by Yeh (2007) and Arnason, Petroff, and Yeh (2009) and Foster, Rossetto, and Allsop (2017). This is probably due to the mild slope of the incoming surge. It is therefore reasonable to conclude that, for a dry bed surge, the inertia component (surge force) can be neglected.

A combination of hydrostatic and hydrodynamic components was suggested by Cross (1967) to compute the total force resulting from wave impact (Table 1). Thus, this study confirms that the actual measured force $F_{\mathrm{x}}$ was less than the one computed using the run-up height $H$, assuming hydrostatic conditions $\left(F_{\mathrm{x}}<F_{\mathrm{x}, \mathrm{H}}\right)$, something which is in agreement with findings by Ramsden (1996), Arnason, Petroff, and Yeh (2009), and Nouri et al. (2010). Furthermore, as shown in Figure 10, the measured values were also higher than the values computed using the wave height $h$ in the absence of the building model $\left(F_{\mathrm{x}}>F_{\mathrm{x}, \mathrm{h}}\right)$.

In addition, for such rapidly varied flows, the hydrostatic and hydrodynamic components cannot be independently identified and any assumption of hydrostatic pressure repartition remains dubious. For these reasons, similarly to Arnason, Petroff, and Yeh (2009), a resistance coefficient $C_{R}$ was used, instead of a "classical" drag coefficient, $C_{D}$. This approach allows to take into account the hydrostatic pressure difference between the back and the front sides of the building, which may contribute a portion of the measured impact force. As recommended by ASCE7 Chapter 6 and Chock (2016), a value of $C_{R}=2.0$ is initially chosen; however, more considerations are presented in Section 5.5.

The presence of the building reduced the wave velocity in the upstream reach of the channel after the impact, producing a backwater effect. Thus, the use of the wave front celerity $U$ in the computation of wave momentum $M$ was not representative and such approach might lead to an overestimation of the resulting load. For this reason, Shafiei, Melville, and Shamseldin (2016) suggested a reduction of the wave front velocity $U$, using the Bernoulli equation. Alternatively, the results presented by Wüthrich et al. (2018) allowed to quantify the decelerating behavior of the wave velocity behind the wave front $\left(V_{m}\right)$ and a more precise estimation of $M$ in time was thus obtained. As such, a modified version of Eq. (2) is

$$
F_{\mathrm{x}, \mathrm{D}}=\frac{1}{2} \rho C_{\mathrm{R}} B \cdot M=\frac{1}{2} \rho C_{\mathrm{R}} B \cdot\left(h V_{\mathrm{m}}^{2}\right)
$$

where $h$ is the wave height measured without the building, $B$ the building width, and $V_{\mathrm{m}}$ the depth-averaged wave velocity, calculated using the formula proposed by Wüthrich et al. (2018). The good agreement (Figure 10) proved experimentally that the horizontal force $F_{\mathrm{x}}$ was proportional to the momentum flux per unit width $\left(M=h V_{\mathrm{m}}{ }^{2}\right.$ ). Equation (3) was tested for three dry bed surges with three different impoundment depths $d_{0}$, as shown in Figure 11. Good agreement is observed for the configurations with higher initial release discharge $\left(d_{0}=0.82 \mathrm{~m}\right)$, resulting into a shorter wave period (impulsive type). On the contrary, for waves with lower initial discharges $\left(d_{0}=0.63\right.$ and especially $\left.0.40 \mathrm{~m}\right)$, an underestimation of the force was observed for higher values of $T \cdot \sqrt{g / d_{0}}$. This underestimation of $F_{\mathrm{X}, \mathrm{D}}$ was particularly

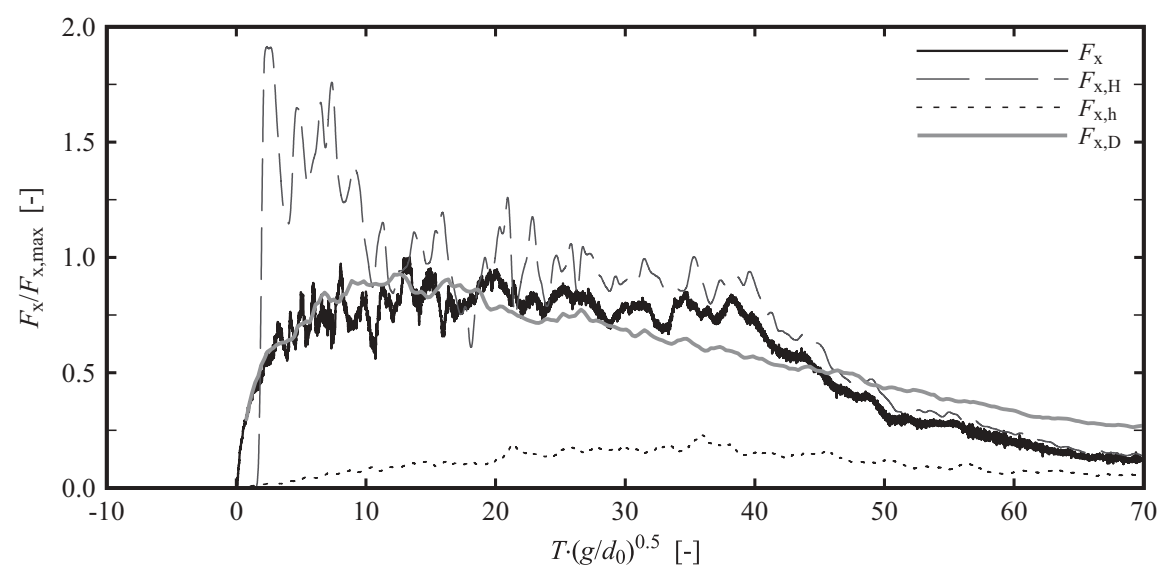

Figure 10. Comparison of tests with hydrostatic and hydrodynamic approach $\left(d_{0}=0.63 \mathrm{~m}\right.$, dry, test 2$) . F_{\mathrm{x}}$ is the measured horizontal force, $F_{\mathrm{x}, \mathrm{H}}$ is the hydrostatic force computed using the run-up height $H$ (with the building), $F_{\mathrm{x}, \mathrm{h}}$ is the hydrostatic force computed using the measured wave height $h(t)$ without the building, and $F_{\mathrm{x}, \mathrm{D}}$ is the hydrodynamic force computed using Eq. (3). 


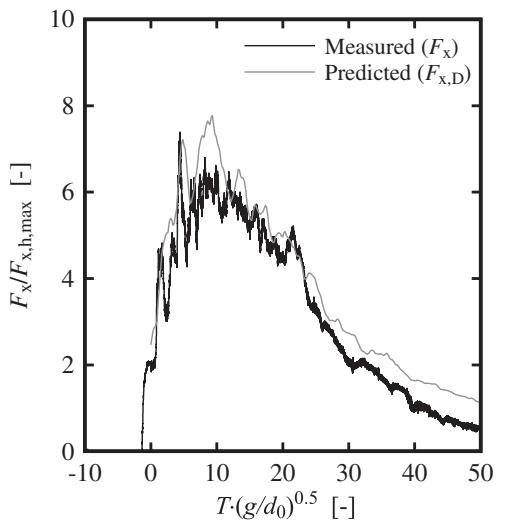

(a)

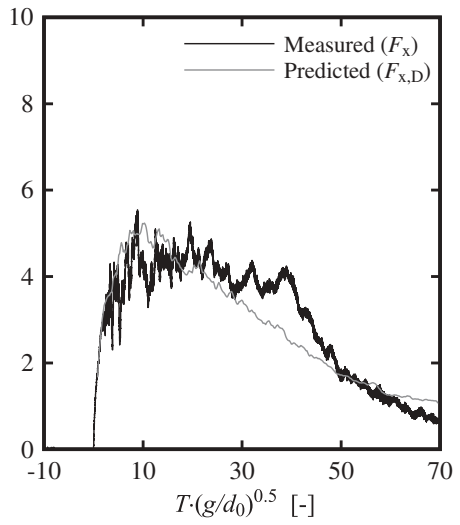

(b)

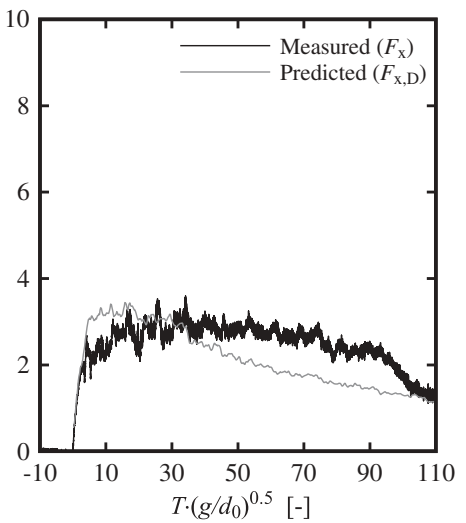

(c)

Figure 11. Comparison of the measured force $\left(F_{\mathrm{x}}\right.$, black) with the values obtained using the momentum equation (Eq. (3)) for three dry bed surges ( $F_{\mathrm{x}, \mathrm{D}}$, gray) (a-c). All forces are normalized using the hydrostatic force $F_{\mathrm{x}, \mathrm{h}, \max }$ corresponding to the maximum wave height $h_{\max }$ without the building. (a) $d_{0}=0.82 \mathrm{~m}, h_{\max }=0.181 \mathrm{~m}$ (test 1), (b) $d_{0}=0.63 \mathrm{~m}, h_{\max }=0.162 \mathrm{~m}$ (test 2), (c) $d_{0}=0.40 \mathrm{~m}, h_{\max }=0.132 \mathrm{~m}$ (test 3 ).

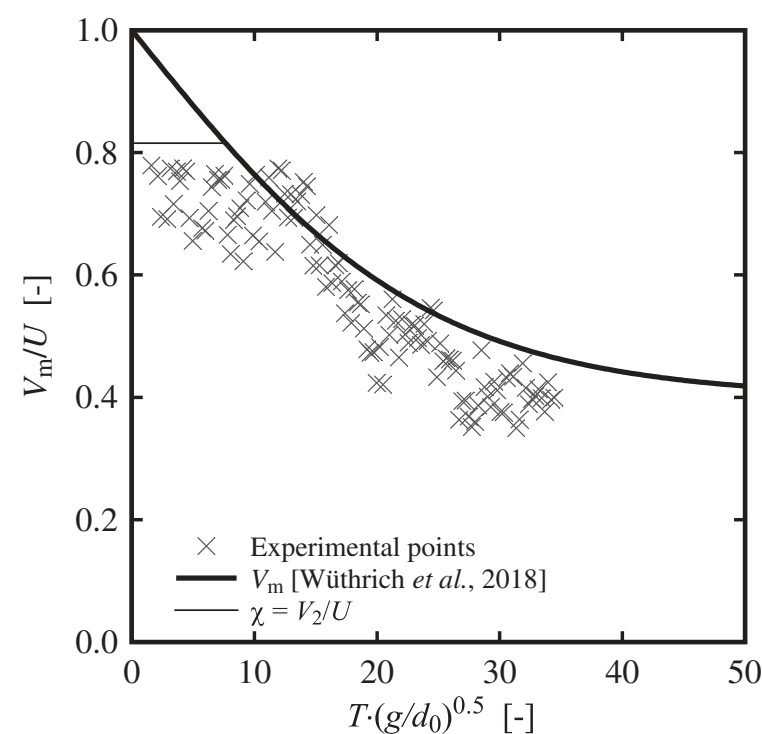

(a)

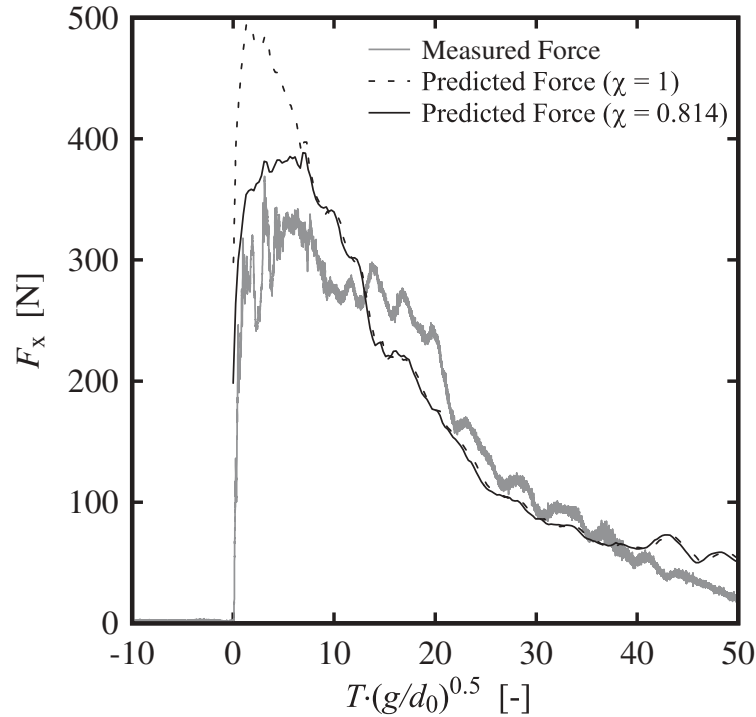

(b)

Figure 12. Wet bore $d_{0}=0.82 \mathrm{~m}, h_{0}=0.05 \mathrm{~m}$ (test 6): (a) model suggested to take into account $\chi_{i}$ (b) example of force overestimation if $x$ is not taken into account.

observed in the post-peak force region for $T$. $\sqrt{g / d_{0}}>30-40$ (Figure 11 ). This is because all parameters used in Eq. (3) refer to the wave properties measured without the presence of the building, whose flow conditions involved higher velocities and lower flow depths. Nevertheless, it is important to point out that the force maxima observed for both measured and predicted values are similar. As such a good representation of the loading process can be obtained with Eq. (3).

\subsection{Wet bed bores}

A bore had a steep turbulent aerated front, similar to a translating hydraulic jump (Figure 6(b)). The general behavior of the forces induced by wet bed bores is shown in Figure 9, and some key differences with the dry bed surges were pointed out at the beginning of Section 5 . In the present study, an initial force overshot was not constantly recorded and, typical of wet bed bores, the increase in horizontal force $F_{\mathrm{x}}$ was proportional to the increase in water depth.

For the estimation of the force acting on the building, the procedure presented in Section 5.1 for the dry bed surge is here applied to wet bed bores. Nevertheless, it was noted that the estimation of the horizontal force $F_{x}$, through Eq. (3), constantly overestimated the measured value by some $20-50 \%$, as shown in Figures 12(b) and 14. This behavior can be attributed to the complexity of the turbulent bore front 


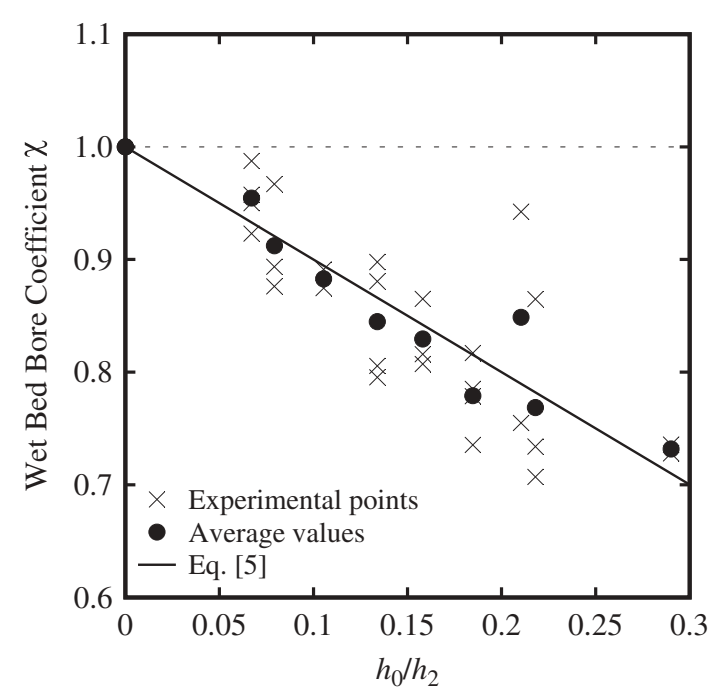

Figure 13. Wet bed bore coefficient $X$ for all tested scenarios

and its aerated profile. Wüthrich et al. (2018) pointed out a discontinuity between the front celerity $U$ and the depth-averaged velocities values $V_{m}$ behind the wave front (Figure 12(a)). This velocity was shown to be similar to the velocity $V_{2}$, which occurs behind the bore front, as predicted by the momentum equation:

$$
v_{2}=U \cdot\left(\frac{h_{2}-h_{0}}{h_{2}}\right)
$$

where $U$ is the front celerity, $h_{2}$ is the wave height behind the front, and $h_{0}$ the initial still water depth. Such discontinuity in velocity values may be a consequence of the presence of the recirculating roller, associated with high energy losses. In addition, the presence of an aerated roller with pulsating and compressible behavior might be partially responsible for the attenuation of the impact forces. For all these reasons, a wet bed force reduction coefficient $\mathrm{X}$ was introduced (Figure 12) and a maximum value of $V_{\mathrm{m}} /$ $U=X$ was herein imposed. The experimental values of
$X$ when the peak forces occurred are presented in Figure 13 and compared to the values of $V_{2}$ obtained from Eq. (4).

Good agreement was found for all experimental points and the average values of $X$ were best approximated by

$$
X=\frac{V_{2}}{U}=1-\frac{h_{0}}{h_{2}}=1-1.073\left(\frac{h_{0}}{d_{0}}\right)^{0.629}
$$

where the bore height $h_{2}$ was obtained using the numerical approximation proposed by Chanson, Aoki, and Maruyama (2000). Thus, the modified momentum flux per unit width, $M^{*}$, taking into account the force reduction coefficient, was computed using

$$
M^{*}(t)=h(t) \cdot\left[\min \left(X U ; V_{\mathrm{m}}(t)\right)\right]^{2}
$$

where $h(t)$ is the time development of the wave profile without the building, $x$ the reduction coefficient, $U$ the bore front celerity, and $V_{m}$ the depth-averaged profile velocity, defined through the expression presented in Wüthrich et al. (2018). For dry bed surges a coefficient $X=1$ can be assumed.

In the computation of the total horizontal force, if the wet bed force reduction coefficient $x$ and the modified momentum $M^{*}$ are introduced, then Eq. (3) leads to

$$
F_{\mathrm{X}, \mathrm{D}}=\frac{1}{2} \rho C_{\mathrm{R}} B \cdot M^{*}
$$

and the prediction of the horizontal force $F_{\mathrm{x}, \mathrm{D}}$ using Eq. (7) is presented in Figure 14 for three bores with different initial still water depths.

\subsection{Maximum force}

For all considered configurations (bores/surges), the experimental force maxima $F_{\mathrm{x}, \max }$ were extracted and compared to the values predicted using Eq. (6), $F_{x, D \text {, max }}$ in Figure 15. These were shown to be proportional to the maximum momentum flux per unit width $M_{\max }^{*}$

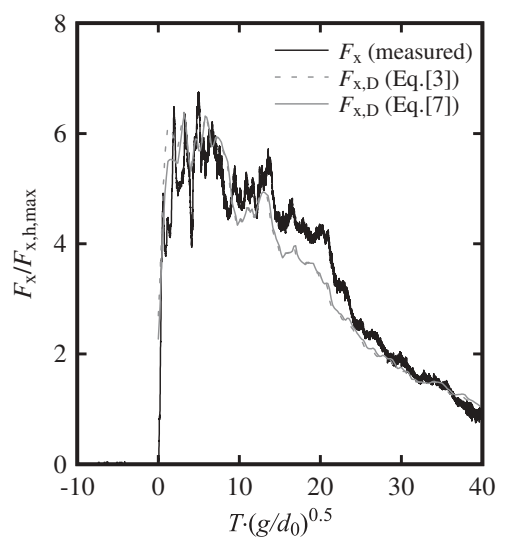

(a)

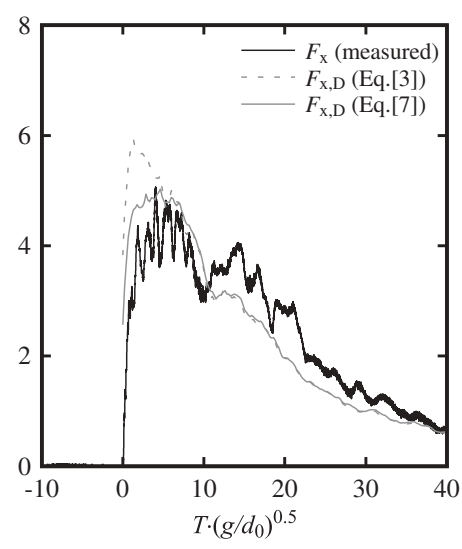

(b)

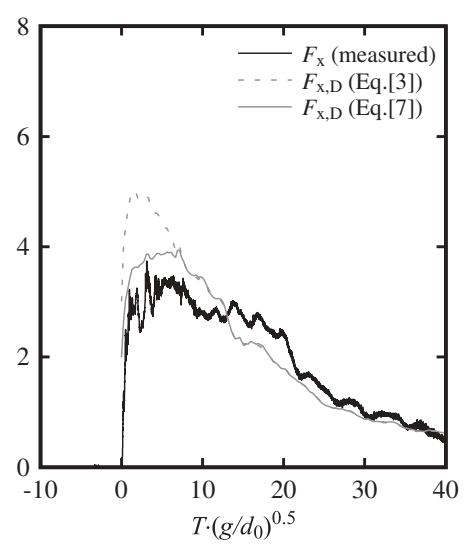

(c)

Figure 14. Comparison of the measured horizontal force with the values obtained from the momentum equation for three wet bed bores. (black: measured value, grey: predicted with Eq. (7), dotted: predicted with $x=1$, Eq. (3). (a) $d_{0}=0.82 \mathrm{~m}, h_{0}=0.01 \mathrm{~m}$, $h_{\text {max }}=0.19 \mathrm{~m} ;$ (b) $d_{0}=0.82 \mathrm{~m}, h_{0}=0.03 \mathrm{~m}, h_{\max }=0.23 \mathrm{~m} ; d_{0}=0.82 \mathrm{~m}, h_{0}=0.05 \mathrm{~m}, h_{\max }=0.26 \mathrm{~m}$ 


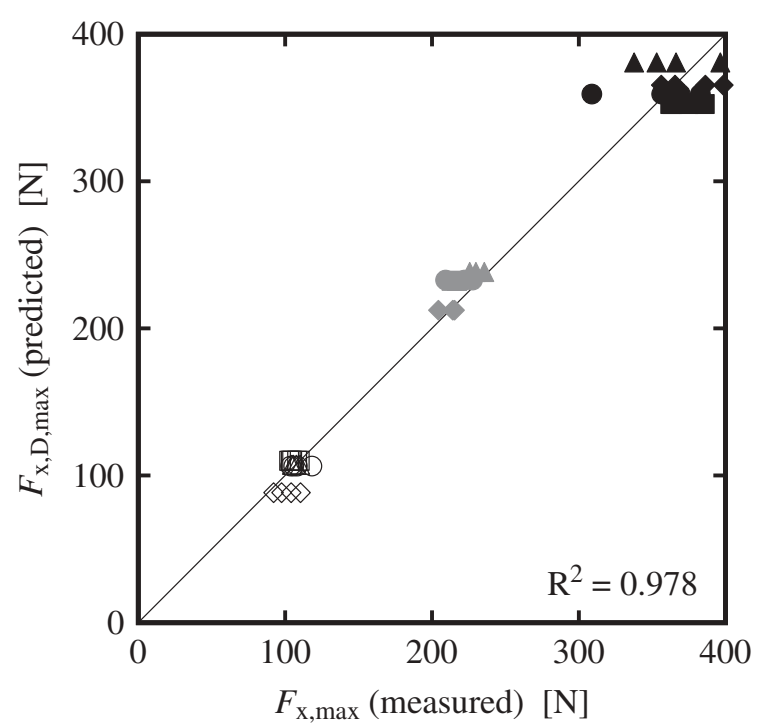

Figure 15. Comparison of maximum measured forces and predicted values obtained with Eq. [8] $-R^{2}=0.978$. Dry bed surges: $\diamond d_{0}=0.82 \mathrm{~m}, \diamond d_{0}=0.63 \mathrm{~m}, \diamond d_{0}=0.40 \mathrm{~m}$; Wet bed bores: $\square d_{0}=0.82 \mathrm{~m} \quad h_{0}=0.01 \mathrm{~m}, \square d_{0}=0.63 \mathrm{~m} h_{0}=0.01 \mathrm{~m}$, $\square$ $d_{0}=0.40 \mathrm{~m} \quad h_{0}=0.01 \mathrm{~m} ; \quad \Delta \quad d_{0}=0.82 \mathrm{~m} \quad h_{0}=0.03 \mathrm{~m}, \quad \Delta \quad d_{0}=0.63 \mathrm{~m}$ $h_{0}=0.03 \mathrm{~m}, \Delta d_{0}=0.40 \mathrm{~m} h_{0}=0.03 \mathrm{~m} ; \quad d_{0}=0.82 \mathrm{~m} h_{0}=0.05 \mathrm{~m}$, $d_{0}=0.63 \mathrm{~m} h_{0}=0.05 \mathrm{~m}, \bigcirc d_{0}=0.40 \mathrm{~m} h_{0}=0.05 \mathrm{~m}$.

resulting in Eq. (8). Results showed a good agreement for all scenarios. Accordingly, for the present case, Eqs. (7) and (8) provide a good estimation of the maximum impact load for both surges and bores on impervious buildings.

$$
F_{\mathrm{X}, \mathrm{D}, \max }=\frac{1}{2} \rho C_{\mathrm{R}} B \cdot M_{\max }^{*}
$$

\subsection{Comparison with previous studies}

The experimental values obtained in the present study were also compared with formulae and meth- odologies found in literature (Table 1). All results are plotted in Figure 16(a) for dry bed surges and in Figure 16(b) for wet bed bores. One can observe that most existing formulae overpredict the herein measured forces. For dry bed surges, relatively good agreement was found using OCADI (2009) and Foster, Rossetto, and Allsop (2017), whereas for wet bed bores, the best agreement is provided by ASCE7-6. It is important to point out that most studies, including Ramsden (1996), Santo and Robertson (2010), and Robertson et al. (2013), were carried out for walls with blockage ratios $\beta=W / B=1$ (Table 1). The difference in resulting forces shown in Figure 16 suggests that in reality this is a 3D phenomenon and that blockage ratio plays an important role in the computation of the total force. Nevertheless, neglecting the effect of the blockage ratio in the computation of the horizontal load is a conservative approach in the design process.

\subsection{Resistance coefficient}

As discussed in Section 5.1, during the impact phase, various components of the total force can be identified, including an initial surge force, hydrodynamic (or drag), and hydrostatic components. Since the process is highly unsteady and rapidly varied, these components are difficult to isolate and estimate. Thus, similarly to Gupta and Goyal (1975) and Arnason, Petroff, and Yeh (2009), a resistance coefficient parameter $C_{R}$, taking into account the surge, hydrostatic, and hydrodynamic components, was used. It is defined as

$$
C_{R}=\frac{2 \cdot F_{x}}{\rho B \boldsymbol{h} V_{m}^{2}}=\frac{2 \cdot F_{x}}{\rho B \boldsymbol{M}^{*}}
$$

where $\rho$ is the fluid density (herein $\rho=1000 \mathrm{~kg} / \mathrm{m}^{3}$ ), B is the building width, $F_{\mathrm{x}}$ is the measured horizontal force,

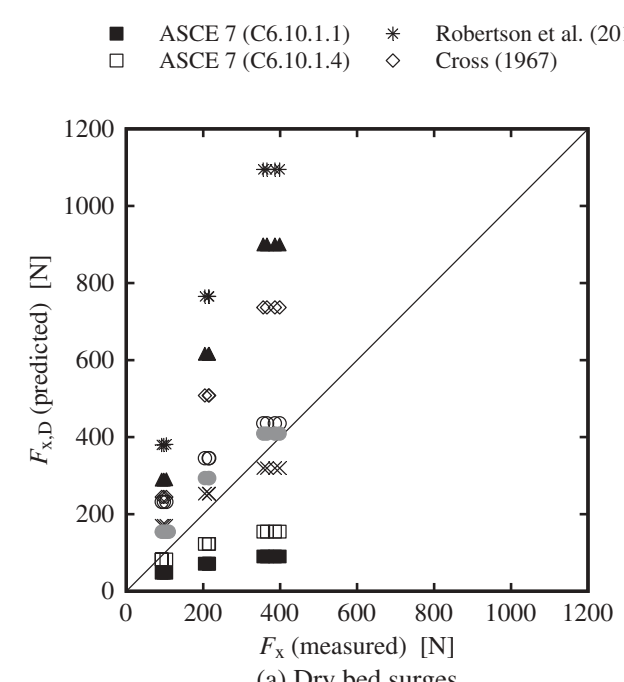

Asakura et al. (2000) $\times$ OCADI (2009)

\ Fujima et al. (2009) $\bullet$ Foster et al. (2017)

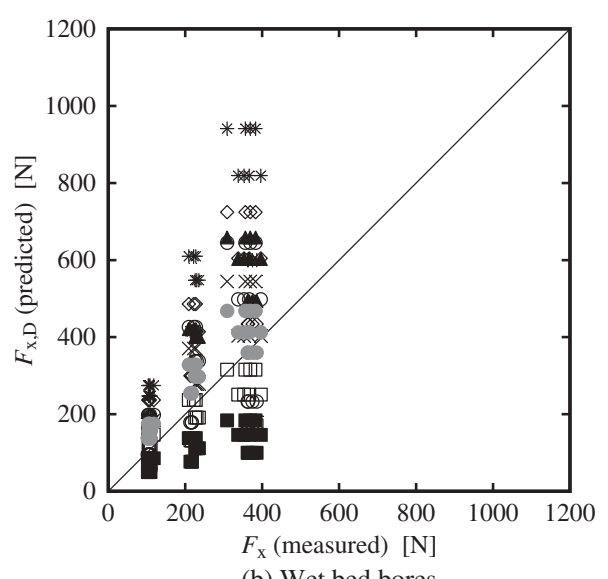

Figure 16. Comparison of measured experimental horizontal force values $\left(F_{\mathrm{x}}\right)$ with those calculated using existing formulae in literature $\left(F_{x}, \mathrm{D}\right)$. 


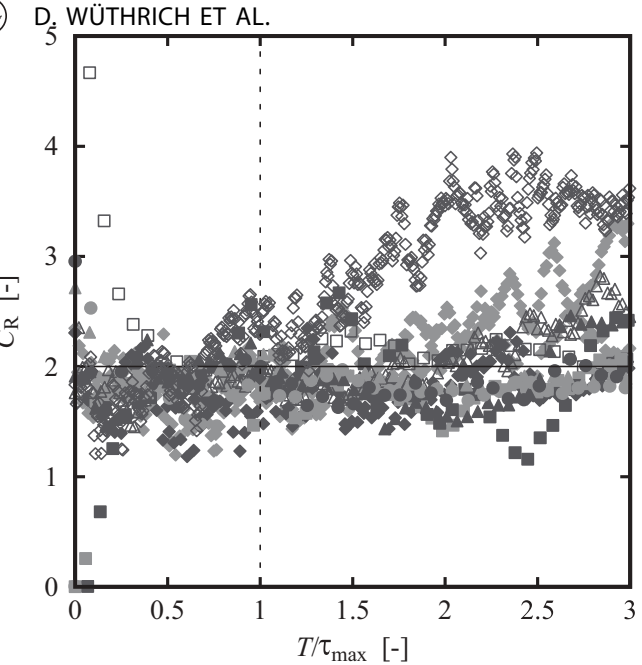

Figure 17. Time history of the resistance coefficient $C_{R}$ during the wave impact for dry bed surges and wet bed bores. Dry bed surges: $\diamond d_{0}=0.82 \mathrm{~m}, \diamond d_{0}=0.63 \mathrm{~m}, \diamond d_{0}=0.40 \mathrm{~m}$; Wet bed bores: $\square d_{0}=0.82 \mathrm{~m} \quad h_{0}=0.01 \mathrm{~m}, \square d_{0}=0.63 \mathrm{~m} \quad h_{0}=0.01 \mathrm{~m}, \square$ $d_{0}=0.40 \mathrm{~m} h_{0}=0.01 \mathrm{~m} ; \Delta d_{0}=0.82 \mathrm{~m} h_{0}=0.03 \mathrm{~m}, \quad \Delta d_{0}=0.63 \mathrm{~m}$ $h_{0}=0.03 \mathrm{~m}, \triangle d_{0}=0.40 \mathrm{~m} h_{0}=0.03 \mathrm{~m} ; \bullet d_{0}=0.82 \mathrm{~m} h_{0}=0.05 \mathrm{~m}$, $d_{0}=0.63 \mathrm{~m} h_{0}=0.05 \mathrm{~m}, \bigcirc d_{0}=0.40 \mathrm{~m} h_{0}=0.05 \mathrm{~m}$.

and $h$ and $V_{\mathrm{m}}$ are the wave height and depth-averaged flow velocity, respectively, measured for the free flow condition without the presence of the building. As mentioned in Section 5.1, the definition presented in Eq. (9) is similar to the drag coefficient $C_{D}$ for the computation of the hydrostatic component; however, the resistance coefficient $C_{R}$ is a function of time rather than a constant value. $C_{R}$ represents the value that would be required to obtain the exact measured value $F_{\mathrm{x}}$ given the height $h$ and velocity $V_{\mathrm{m}}$ of the wave without the presence of the building. If $C_{R}>2.0$, then the force is underestimated, whereas for $C_{R}<2.0$ the force is overestimated. For longer times, an increase in the value of $C_{R}$ is observed especially for dry bed surges, suggesting an underestimation of the horizontal force in the quasi-steady hydrodynamic phase when using the conventional value of $C_{R}=2.0$ (Figure 11 (c)). In Figure $17 \tau_{\max }$ represents the time at which the maximum force occurs and the chosen normalization $T /$ $\tau_{\max }$ allows to express the value of $C_{R}$ at the moment of the force peak $\left(T / \tau_{\max }=1\right)$. Good agreement is observed for all scenarios, and a constant value of $C_{R}=2.0$, suggested by numerous design codes including FEMA (FEMA 55, 2000), CCH (2000), and ASCE7-6, seems appropriate. These findings are confirmed in Figure 18 , where values of $C_{R}$ at $T / \tau_{\max }=1$ are presented for various surges and bores tested. For wet bed bores, the independency of the resistance coefficient from the initial still water depth $h_{0}$ is shown in Figure 18.

\section{In-depth force analysis}

An in-depth analysis of the measured horizontal force in the $x$-direction was conducted. The main parameters discussed are (1) time to peak, $\tau_{\max }$ corresponding to the time from wave arrival $\left(t_{0}\right)$

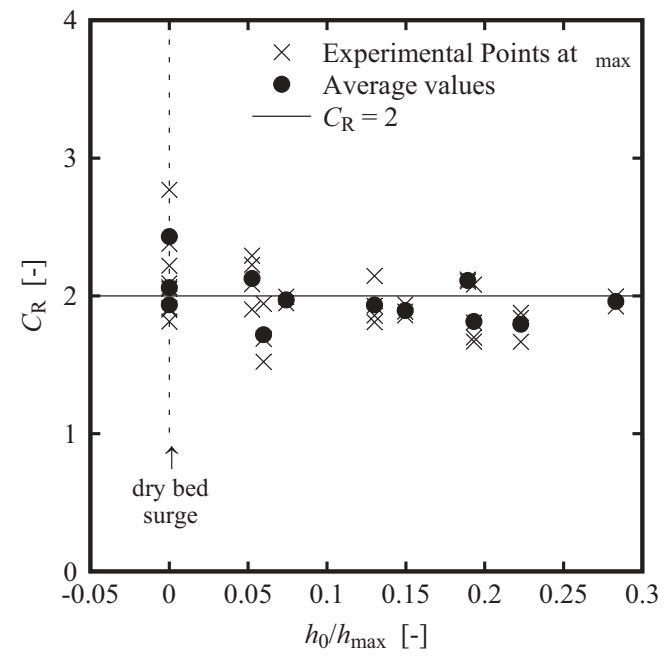

Figure 18. Resistance coefficient, $C_{R}$, determined at $\tau_{\max }$ for both wet bed bores and dry bed surges.

to the force peak; (2) the wave height at maximum force, $h_{\mathrm{M}}$, at which the maximum horizontal force is measured; and (3) the impulse, $I$, transferred from the wave to the building. These parameters are schematically presented in Figure 19.

\subsection{Time to peak $\tau_{\max }$}

The "time to peak", $\tau_{\max }$, represents the time interval between the initial impact $\left(T=t-t_{0}=0\right)$ and the maximum horizontal force $F_{x, \max }$. The values of $\tau_{\max }$ obtained for all tests are presented in Figure 20 as a function of $h_{0} / h_{\max }$ where $h_{0} /$ $h_{\max }=0$ represents the dry bed surges and $h_{0} /$ $h_{\max }>0$ the wet bed bores. Results showed larger normalized values of $\tau_{\max }$ for dry bed surges $\left(h_{0} /\right.$ $h_{\max }=0$ ), ranging from $5<\tau_{\max } \sqrt{g / d_{0}}<35$, whereas for wet bed bores $\left(h_{0} / h_{\max }>0\right)$, almost all maxima occurred instantaneously for $0<\tau_{\max } \sqrt{g / d_{0}}<5$. These observations clearly confirmed a substantial difference between surges and bores in terms of their respective celerity, proving thus that maximum force values occur before those recorded in the wet bed scenario, resulting therefore in steeper average gradients $\mathrm{d} F / \mathrm{d} t$.

\subsection{Wave height at maximum force $h_{M}$}

An important parameter in the design of tsunami resistant buildings is the wave height $h$ at which the maximum force $F_{x, \max }$ occurs $\left(T=\tau_{\max }\right)$, normalized with the maximum wave height $h_{\max }$ without the building.

$$
h_{\mathrm{M}}=\frac{h\left(T=\tau_{\max }\right)}{h_{\max }}
$$

The results obtained from the tests are presented in Figure 21. These are also compared to the design 


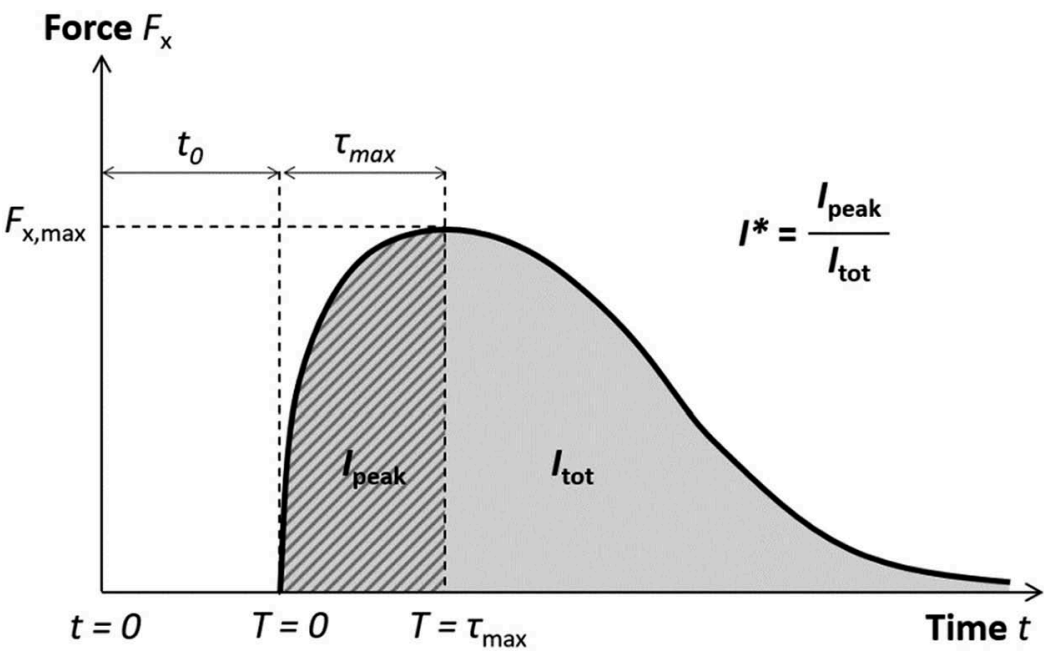

Figure 19. Definition sketch of parameters used in the force analysis.

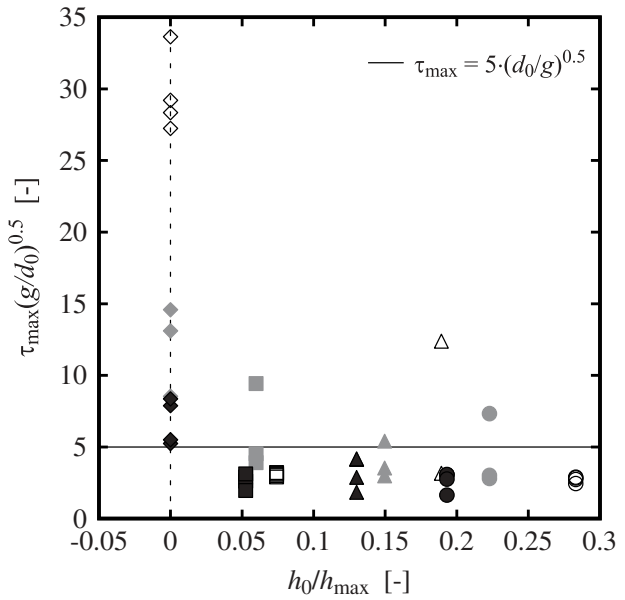

Figure 20. Normalised values of the time to peak $\left(\tau_{\max }\right)$ for the wet bed bores and dry bed surges. Dry bed surges: $d_{0}=0.82 \mathrm{~m}, \diamond d_{0}=0.63 \mathrm{~m}, \diamond d_{0}=0.40 \mathrm{~m}$; Wet bed bores: $d_{0}=0.82 \mathrm{~m} \quad h_{0}=0.01 \mathrm{~m}, \square d_{0}=0.63 \mathrm{~m} \quad h_{0}=0.01 \mathrm{~m}, \square d_{0}=0.40 \mathrm{~m}$ $h_{0}=0.01 \mathrm{~m} ; \Delta d_{0}=0.82 \mathrm{~m} h_{0}=0.03 \mathrm{~m}, \Delta d_{0}=0.63 \mathrm{~m} h_{0}=0.03 \mathrm{~m}, \Delta$ $d_{0}=0.40 \mathrm{~m} \quad h_{0}=0.03 \mathrm{~m} ;-d_{0}=0.82 \mathrm{~m} \quad h_{0}=0.05 \mathrm{~m}, \quad d_{0}=0.63 \mathrm{~m}$ $h_{0}=0.05 \mathrm{~m}, \bigcirc d_{0}=0.40 \mathrm{~m} h_{0}=0.05 \mathrm{~m}$.

guidelines of the ASCE7-6, according to which the maximum hydrodynamic load occurs at the moment when the $2 / 3$ of the maximum inundation depth is reached, i.e. when $h=h_{\mathrm{M}}=2 / 3 h_{\max }$. Results showed relatively good agreement for dry bed surges $\left(h_{0} /\right.$ $h_{\max }=0$ ) with an average value of $h_{\mathrm{M}}=0.71 \mathrm{~m}$. However, for increasing values of $h_{0} / h_{\max }$, the choice of $h_{\mathrm{M}}=2 / 3$ becomes less conservative. Since the maximum force is proportional to the maximum momentum, as shown in Eq. (5), these results are in line with the findings of Wüthrich et al. (2018), who measured the momentum flux of bores and surges without the presence of the building.

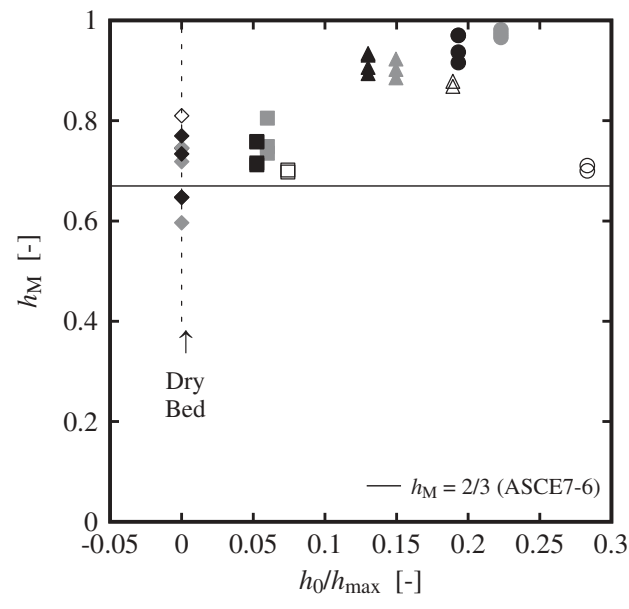

Figure 21. Wave height at maximum force $h_{M}$ at which the maximum force $F_{x, \max }$ occurs. Experimental data and comparison with design guidelines of the ASCE7-6. Dry bed surges: $\diamond d_{0}=0.82 \mathrm{~m}, \diamond d_{0}=0.63 \mathrm{~m}, \diamond d_{0}=0.40 \mathrm{~m}$; Wet bed bores: $d_{0}=0.82 \mathrm{~m} \quad h_{0}=0.01 \mathrm{~m}, \square d_{0}=0.63 \mathrm{~m} \quad h_{0}=0.01 \mathrm{~m}, \square d_{0}=0.40 \mathrm{~m}$ $h_{0}=0.01 \mathrm{~m} ; \Delta d_{0}=0.82 \mathrm{~m} h_{0}=0.03 \mathrm{~m}, \Delta d_{0}=0.63 \mathrm{~m} h_{0}=0.03 \mathrm{~m}, \Delta$ $d_{0}=0.40 \mathrm{~m} \quad h_{0}=0.03 \mathrm{~m} ; \bullet \quad d_{0}=0.82 \mathrm{~m} h_{0}=0.05 \mathrm{~m}, \quad d_{0}=0.63 \mathrm{~m}$ $h_{0}=0.05 \mathrm{~m}, \bigcirc d_{0}=0.40 \mathrm{~m} h_{0}=0.05 \mathrm{~m}$.

\subsection{Impulse I}

The product of force $F$ and time $t$ is known as Impulse I. For the present case, the total impulse $I_{\text {tot }}$ is the integral of the force $F_{\mathrm{x}}$ over time, until the upper limit $T=100 \cdot \sqrt{\frac{d_{0}}{g}}$ is reached. This value was chosen as it represented the minimum duration that allowed to capture the loading data for all waves. The total impulse is thus expressed as

$$
I_{\text {tot }}=\int_{0}^{100 \sqrt{\frac{d_{0}}{g}}} F_{\mathrm{x}}(T) \mathrm{d} T
$$




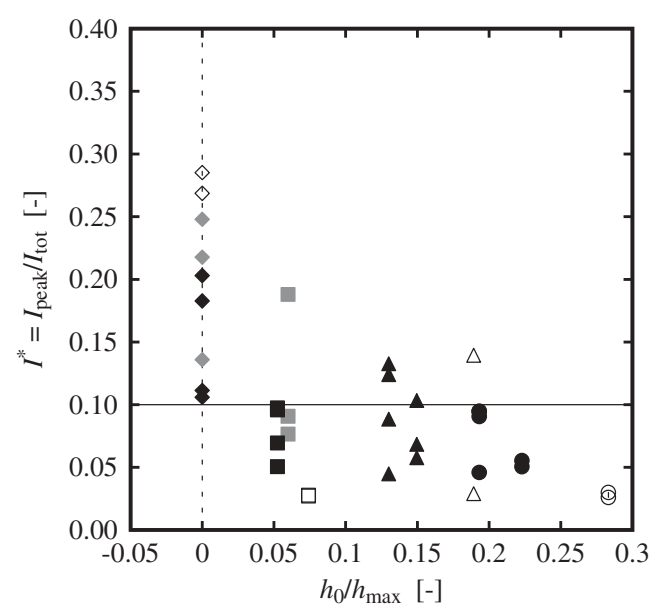

Figure 22. Values of $I^{*}=I_{\text {peak }} / I_{\text {tot }}$ computed for dry bed surges $\left(h_{0} / h_{\max }=0\right)$ and wet bed bores. Dry bed surges: $d_{0}=0.82 \mathrm{~m}, \diamond d_{0}=0.63 \mathrm{~m}, \diamond d_{0}=0.40 \mathrm{~m}$; Wet bed bores: $d_{0}=0.82 \mathrm{~m} \quad h_{0}=0.01 \mathrm{~m}, \square d_{0}=0.63 \mathrm{~m} \quad h_{0}=0.01 \mathrm{~m}, \square d_{0}=0.40 \mathrm{~m}$ $h_{0}=0.01 \mathrm{~m} ; \Delta d_{0}=0.82 \mathrm{~m} h_{0}=0.03 \mathrm{~m}, \Delta d_{0}=0.63 \mathrm{~m} h_{0}=0.03 \mathrm{~m}, \Delta$ $d_{0}=0.40 \mathrm{~m} \quad h_{0}=0.03 \mathrm{~m} ; \bigcirc d_{0}=0.82 \mathrm{~m} \quad h_{0}=0.05 \mathrm{~m}, \quad d_{0}=0.63 \mathrm{~m}$ $h_{0}=0.05 \mathrm{~m}, \bigcirc d_{0}=0.40 \mathrm{~m} h_{0}=0.05 \mathrm{~m}$.

This quantity also represents the area of the surface below the curve, as shown in Figure 19. Given Newton's second law $(F=m \cdot a=m \cdot \Delta V / \Delta t)$, the impulse can be expressed as $I=F \cdot \Delta t=m \cdot \Delta V$, corresponding to the change in momentum. The impulse experienced by the building $I_{\text {tot }}$ equals therefore the exchange in momentum with the incoming wave. To better define the amount of impulse that is transferred to the building before the peak force occurs, a parameter, $I_{\text {peak, }}$ is defined as the integral between $0<T<\tau_{\max }$. The latter represents the area of the surface below the curve up to the moment when $F_{x, \max }$ is recorded (Figure 19).

$$
I_{\text {peak }}=\int_{0}^{\tau_{\max }} F(T) \mathrm{d} T
$$

Both the total impulse and the peak impulse calculated for the tests are shown in Figure 22. These results suggest that the impulse transferred to the building before the occurrence of the force peak is only a small portion of the total impulse. A parameter $I^{*}$ is defined as the ratio between the peak impulse $I_{\text {peak }}$ and the total impulse $I_{\text {tot, }}$ corresponding the portion of impulse that is transferred to the building before the maximum force occurs.

$$
I^{*}=\frac{I_{\text {peak }}}{I_{\text {tot }}}
$$

Its values for the current experimental tests are presented in Figure 22. A different behavior can be observed between surges $\left(h_{0} / h_{\max }=0\right)$ and bores $\left(h_{0} / h_{\max }>0\right)$. In fact, for bores, less than $10-15 \%$ of the total impulse is transferred to the building before the peak. In contrast, for surges this can reach $30-35 \%$. This difference is also a consequence of the

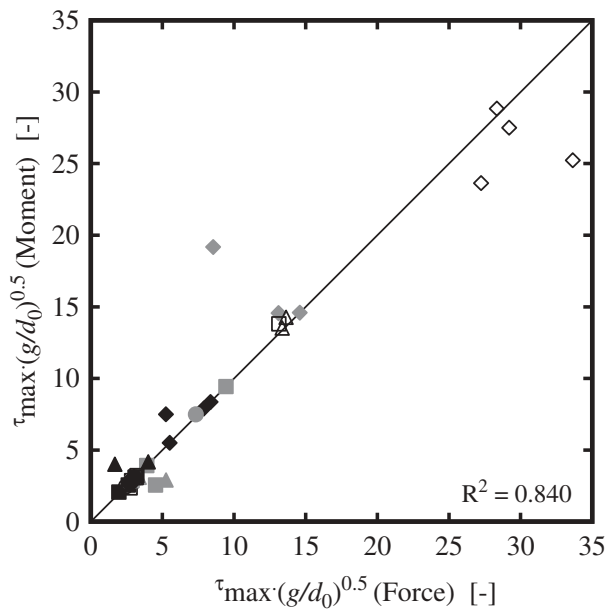

Figure 23. Time of occurrence of maximum horizontal force $F_{\mathrm{x}}$ and maximum moment $M_{\mathrm{y}}$. Dry bed surges: $\diamond d_{0}=0.82 \mathrm{~m}$, $\diamond d_{0}=0.63 \mathrm{~m}, \diamond d_{0}=0.40 \mathrm{~m}$; Wet bed bores: $\square d_{0}=0.82 \mathrm{~m}$ $h_{0}=0.01 \mathrm{~m}, \square d_{0}=0.63 \mathrm{~m} h_{0}=0.01 \mathrm{~m}, \square d_{0}=0.40 \mathrm{~m} h_{0}=0.01 \mathrm{~m} ; \boldsymbol{\Delta}$ $d_{0}=0.82 \mathrm{~m} h_{0}=0.03 \mathrm{~m}, \Delta d_{0}=0.63 \mathrm{~m} h_{0}=0.03 \mathrm{~m}, \Delta d_{0}=0.40 \mathrm{~m}$ $h_{0}=0.03 \mathrm{~m} ; \bullet \quad d_{0}=0.82 \mathrm{~m} h_{0}=0.05 \mathrm{~m}, \bigcirc d_{0}=0.63 \mathrm{~m} h_{0}=0.05 \mathrm{~m}, \bigcirc$ $d_{0}=0.40 \mathrm{~m} h_{0}=0.05 \mathrm{~m}$.

time to peak force values that were previously discussed in Section 6.1 and it is in agreement with Bullock et al. (2007), for whom $I_{\text {peak }}<0.3 I_{\text {tot }}$.

\section{Moments and cantilever arm}

Any force applied outside of the centroid of an area produces a moment that is directly proportional to its application distance, called cantilever $\operatorname{arm} L_{z}$. In this study, only moments in the transversal direction $\left(M_{\mathrm{y}}\right)$ were considered. Since their magnitude was too low to be considered relevant, $M_{\mathrm{x}}$ and $M_{\mathrm{z}}$ were neglected, as previously shown in Figure 9. Despite some small scattering, results showed that overall the maximum moment $M_{y, \max }$ occurred at the same time $t$ as the maximum horizontal force $F_{\mathrm{x}, \mathrm{max}}$ as shown in Figure 23.

The cantilever arm corresponds to the application point of the horizontal force, whose magnitude was identified in Section 5. As shown in Figure 1, the reference point $\left(L_{z}=0\right)$ coincided with the channel bottom. Given the simultaneous occurrence of $F_{x, \max }$ and $M_{\mathrm{y}, \max }$ as shown in Figure 23 , the value of $L_{z}$ arm at $T=\tau_{\max }$ can be obtained using Eq. (14). The values are normalized with the maximum wave height without the building $h_{\max }$. The cantilever arm of all experimental points, including both dry bed surges and wet bed bore, is presented in Figure 24.

$$
\left(L_{\mathrm{z}}\right)_{\tau_{\max }}=\frac{M_{\mathrm{y}, \max }}{F_{\mathrm{x}, \max }}
$$

These results showed that, for all tested scenarios, the cantilever arm had a fairly constant magnitude, ranging between 0.9 and $1.2 h_{\max }$, with an average value of $1.15 h_{\max }$ where $h_{\max }$ is the wave height 


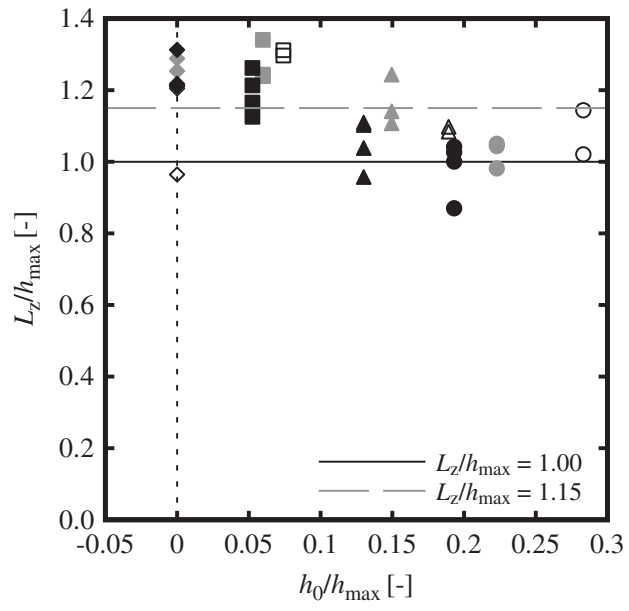

Figure 24. Cantilever arm $L_{z}$ computed for both dry bed surges and wet bed bores for $T=\tau_{\max }$. Dry bed surges: $d_{0}=0.82 \mathrm{~m}, \diamond d_{0}=0.63 \mathrm{~m}, \diamond d_{0}=0.40 \mathrm{~m}$; Wet bed bores: $d_{0}=0.82 \mathrm{~m} h_{0}=0.01 \mathrm{~m}, \square d_{0}=0.63 \mathrm{~m} \quad h_{0}=0.01 \mathrm{~m}, \square d_{0}=0.40 \mathrm{~m}$ $h_{0}=0.01 \mathrm{~m} ; \Delta d_{0}=0.82 \mathrm{~m} h_{0}=0.03 \mathrm{~m}, \Delta d_{0}=0.63 \mathrm{~m} h_{0}=0.03 \mathrm{~m}, \Delta$ $d_{0}=0.40 \mathrm{~m} \quad h_{0}=0.03 \mathrm{~m} ; \bigcirc \quad d_{0}=0.82 \mathrm{~m} \quad h_{0}=0.05 \mathrm{~m}$, $\quad d_{0}=0.63 \mathrm{~m}$ $h_{0}=0.05 \mathrm{~m}, \bigcirc d_{0}=0.40 \mathrm{~m} h_{0}=0.05 \mathrm{~m}$.

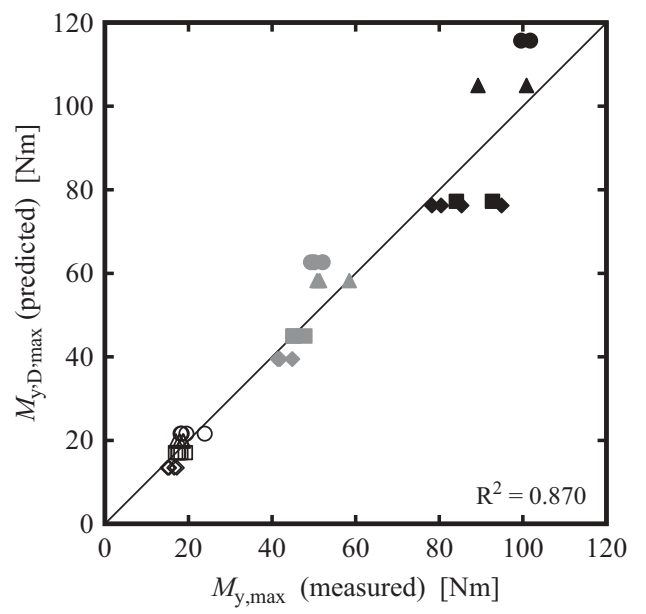

Figure 25. Comparison of experimental moments with the values predicted through Eq. [15]. Dry bed surges: $d_{0}=0.82 \mathrm{~m}, \diamond d_{0}=0.63 \mathrm{~m}, \diamond d_{0}=0.40 \mathrm{~m}$; Wet bed bores: $d_{0}=0.82 \mathrm{~m} \quad h_{0}=0.01 \mathrm{~m}, \square d_{0}=0.63 \mathrm{~m} \quad h_{0}=0.01 \mathrm{~m}, \square d_{0}=0.40 \mathrm{~m}$ $h_{0}=0.01 \mathrm{~m} ; \Delta d_{0}=0.82 \mathrm{~m} h_{0}=0.03 \mathrm{~m}, \Delta d_{0}=0.63 \mathrm{~m} h_{0}=0.03 \mathrm{~m}, \Delta$ $d_{0}=0.40 \mathrm{~m} h_{0}=0.03 \mathrm{~m} ; \quad d_{0}=0.82 \mathrm{~m} h_{0}=0.05 \mathrm{~m}$, $\quad d_{0}=0.63 \mathrm{~m}$ $h_{0}=0.05 \mathrm{~m}, \bigcirc d_{0}=0.40 \mathrm{~m} h_{0}=0.05 \mathrm{~m}$.

for the case without building. It could therefore be assumed that the maximum horizontal force defined in Section 5 was applied at a height that corresponded to 1.15 of the maximum wave height without the presence of the building, something which leads to Eq. (15):

$$
M_{\mathrm{y}, \mathrm{D}, \max }=F_{\mathrm{x}, \mathrm{D}, \max } \cdot 1.15 h_{\max }
$$

The prediction of the maximum moment $M_{\mathrm{y}, \mathrm{D} \text {, } \max }$ through Eq. (15) is compared to the experimental data in Figure 25: good agreement for all scenarios can be observed.

\section{Conclusions}

Post-tsunami forensic engineering field surveys have shown that a specific building design can limit damages to vital infrastructures and provide vertical shelters. At present, several experimental studies and few design guidelines are available to engineers. However, disagreement with measured data and an overestimation of the forces were observed. The purpose of this study is to characterize the loading process for free-standing buildings in terms of the wave's hydrodynamic properties.

In this experimental study, a vertical release technique was used to reproduce tsunami-like flows, similar to those produced with dam-break scenarios. The building was reproduced through a $0.3 \times 0.3 \mathrm{~m}$ freestanding impervious building model made of aluminum plates, sufficiently rigid to minimize structural response. Wave hydrodynamics was investigated using Ultrasonic distance Sensors (US), which recorded the water level upstream of the building. Forces and moments acting on the building were measured using a force plate, which provided a detailed record of the loading history.

Both dry bed surges and wet bed bores were systematically tested. Dry bed surges were characterized by a non-aerated front followed by a constant increase in water depth, whereas bores presented a turbulent aerated roller propagating along the channel associated with a sudden rise in water depth. Furthermore, surges had higher front velocities, whereas bores had greater wave heights. For all scenarios, the wave impact was characterized by high splashes and significant turbulent air entrainment on the upstream side of the building. Following the initial impact, quasi-steady hydrodynamic flow conditions around the building were observed.

During the impact, only forces and moments in the stream-wise direction $\left(F_{\mathrm{x}}, M_{\mathrm{y}}\right)$ were considered as the others were found to be too small to be relevant. The following conclusions can be drawn from this study:

(1) For dry bed surges, the horizontal force $F_{x}$ was shown to be proportional to the momentum flux per unit width $M=h V_{\mathrm{m}}{ }^{2}$, where $h$ and $V_{\mathrm{m}}$ are the height and velocity of the wave without the building. Equation (3) describes well the horizontal forces for dry bed surges.

(2) The application of Eq. (3) to wet bed bores leads to an overestimation of the maximum load. The presence of an aerated roller, similar to a translating hydraulic jump, associated with internal energy dissipation, showed a reduction in flow velocities behind the wave front. For this, a wet bed force reduction coefficient $\mathrm{X}$ (Eq. (5)) was 
introduced and a modified momentum flux $M^{*}$ defined. This approach gave a better agreement for all experiments (Eq. (7)). The use of Eq. (7) also showed lower forces compared to ASCE7-6, thus proving a conservative approach in the design of coastal structures subject to tsunami hazard.

(3) Since the wave impact process is highly unsteady and rapidly varied, the hydrostatic, hydrodynamic (or drag), and surge components are difficult to isolate and further estimate. For this reason, the drag coefficient, $C_{D}$, was herein replaced with a resistance coefficient $C_{R}$. The latter was a function of time and an average value $C_{R}=2.0$ was shown to be appropriate at the occurrence of the maximum horizontal force, $F_{x, \max }$.

(4) The maximum horizontal force was shown to be proportional to the maximum modified momentum flux per unit width $M^{*}$ max. A good estimation for both surges and bores is represented by Eq. (8).

(5) Additional parameters were also introduced and discussed. The time to peak $\tau_{\text {max }}$ defined as the time lap between the arrival of the wave $t_{0}$ and $F_{\mathrm{x}}$, max, showed that the maximum force occurred before for wet bed bores than for dry bed surges. This implied that the initial force gradient was higher for bores than for surges. Especially for bores, the maximum force $F_{\mathrm{x} \text {,max }}$ also occurred at a relative wave height $h_{\mathrm{M}}$ that was higher than the $2 / 3$ value suggested by the ASCE 7-6. The impulse $(I=F \cdot t)$ represented the exchange in momentum transferred from the wave to the building. Similar values were observed for surges and bores with the same initial conditions; however for bores only $10-15 \%$ of the total impulse were transferred to the building before the occurrence of the maximum horizontal force.

(6) The maximum force $F_{x, \max }$ and maximum moment $M_{y, \max }$ were shown to occur simultaneously. The application point of the force (cantilever arm) was defined as $L_{z}=M_{y, \max } / F_{\mathrm{x}}$, max and, for all scenarios, an average value of $1.15 h_{\max }$ was found. This allowed to predict the moment $M_{y}$ using Eq. (15).

(7) This research paper provides some relevant information for the design of safer, impervious, near-shore structures. However, the impact of extreme hydrodynamic events on a free-standing building remains only partially understood and the effect of blockage ratio, openings and over-topping on the loading process should be further assessed and quantified.

\section{Acknowledgment}

The valuable inputs of Prof. Eugen Brühwiler (MCS-EPFL) are acknowledged.

\section{Disclosure statement}

No potential conflict of interest was reported by the authors.

\section{Funding}

This work was supported by the Swiss National Science Foundation (SNSF) [grant numbers 200021_149112/1 and 200021_149112/2].

\section{Notation}

$B$ building width and depth [m]

$C_{\mathrm{D}}$ drag coefficient [-]

$C_{R}$ resistance coefficient [-]

$d_{0}$ equivalent impoundment depth [m]

$F$ force [N]

$f$ frequency of the flow $[\mathrm{Hz}]$

$F_{\mathrm{x}}$ force in the horizontal direction [N]

$F_{\mathrm{X}, \mathrm{D}}$ horizontal hydrodynamic force $[\mathrm{N}]$

$F_{\mathrm{X}, \mathrm{D}, \max }$ maximum computed horizontal force $[\mathrm{N}]$

$F_{\mathrm{X}, \mathrm{H}}$ hydrostatic force computed using $h[\mathrm{~N}]$

$F_{\mathrm{x}, \mathrm{h}}$ hydrostatic force computed using $h$ [N]

$F_{\mathrm{x}, \mathrm{h} \text {,max }}$ hydrostatic force computed using $h_{\max }[\mathrm{N}]$

$F_{\mathrm{x}, \max }$ maximum horizontal force $[\mathrm{N}]$

$F_{\mathrm{y}}$ force in the transversal direction $[\mathrm{N}]$

$F_{\mathrm{z}}$ force in the vertical direction $[\mathrm{N}]$

g gravitational constant $(g=9.81)\left[\mathrm{m} / \mathrm{s}^{2}\right]$

$H$ wave (run-up) heights with the building [m]

$h$ wave height without the building [m]

$h_{0}$ initial still water depth [m]

$h_{2}$ plateau height for incoming wet bed bore [m]

$H_{\mathrm{B}}$ building height [m]

$h_{\mathrm{M}}$ wave height at which $F_{\mathrm{x}, \max }$ occurred [m]

$h_{\max }$ maximum wave height without the building [m]

I impulse [Ns]

$I^{*}$ relative impulse, defined as $I^{*}=I_{\text {peak }} / I_{\text {tot }}$

$I_{\text {peak }}$ impulse between $T=0$ and $T=\tau_{\max }[\mathrm{Ns}]$

$I_{\text {tot }}$ total measured impulse [Ns]

$I_{\text {tot,D }}$ total computed impulse $[\mathrm{Ns}]$

$L_{\mathrm{z}}$ lever arm, defined as $L_{\mathrm{z}}=M_{\mathrm{y}} / F_{\mathrm{x}}[\mathrm{m}]$

$m$ mass [kg]

$M$ momentum flux per unit width $\left[\mathrm{m}^{3} / \mathrm{s}^{2}\right]$

$M^{*}$ reduced momentum flux per unit width $\left[\mathrm{m}^{3} / \mathrm{s}^{2}\right]$

$M_{\max }$ maximum momentum flux per unit width $\left[\mathrm{m}^{3} / \mathrm{s}^{2}\right.$ ]

$M_{\mathrm{x}}$ moment around the $x$-axis $[\mathrm{Nm}]$

$M_{\mathrm{y}}$ moment around the $y$-axis $[\mathrm{Nm}]$

$M_{\mathrm{y}, \mathrm{D}}$ computed moment around the $y$-axis [Nm]

$M_{\mathrm{y}, \mathrm{D}, \max }$ maximum computed moment around the $y$-axis $[\mathrm{Nm}]$

$M_{\mathrm{y} \text {, max }}$ maximum moment around the $y$-axis [Nm]

$M_{\mathrm{z}}$ moment around the $z$-axis $[\mathrm{Nm}]$

St Strouhal number, defined as $S t=f \cdot B / U$

$T$ shifted time, such that $T=t-t_{0}[\mathrm{~s}]$

$t$ time [s]

$t_{0}$ arrival time of the wave [s]

$U$ wave front celerity $[\mathrm{m} / \mathrm{s}]$

$v$ flow velocity $[\mathrm{m} / \mathrm{s}]$

$V_{\mathrm{m}}$ depth-averaged profile velocity $[\mathrm{m} / \mathrm{s}$ ]

$W$ channel width [m]

$x$ longitudinal coordinate [m]

$y$ transversal coordinate [m]

$z$ vertical coordinate $[\mathrm{m}]$

$\beta$ blockage ratio, defined as $\beta=W / B[-]$

$\rho$ water density $\left[\mathrm{kg} / \mathrm{m}^{3}\right]$ 
$\tau_{\max }$ shifted time at which $F_{\mathrm{x}, \max }$ occurs [s]

$X$ wet bed reduction coefficient $[-]$

\section{ORCID}

Davide Wüthrich (D) http://orcid.org/0000-0003-1974-3560

loan Nistor (D) http://orcid.org/0000-0001-8436-4781

Anton J. Schleiss (i) http://orcid.org/0000-0003-1559-5740

\section{References}

Al-Faesly, T., D. Palermo, I. Nistor, and A. Cornett. 2012. "Experimental Modeling of Extreme Hydrodynamic Forces on Structural Models." International Journal of Protective Structures 3 (4): 477-506. doi:10.1260/20414196.3.4.477.

Arnason, H., C. Petroff, and H. Yeh. 2009. "Tsunami Bore Impingement onto a Vertical Column." Journal of Disaster Research 4 (6): 391-403. doi:10.20965/jdr.2009. p0391.

Asakura, R., K. Iwase, T. Ikeya, M. Takao, K. Kaneto, N. Fujii, and M. Omori. 2000. "An Experimental Study on Wave Force Acting on On-Shore Structures Due to Overflowing Tsunamis." Proceedings of Coastal Engineering 47: 911-915. in Japanese. doi:10.2208/ proce1989.47.911.

ASCE 7-6 (Structural Engineering Institute). 2016. "Minimum Design Loads for Buildings and Other Structures." Asce/Sei 7-16. Reston, VA.

Blevins, R. D. 1984. Applied Fluid Dynamics Handbook, 568. New York: Van Nostrand Reinhold.

Bullock, G. N., C. Obhrai, D. H. Peregrine, and H. Bredmose. 2007. "Violent Breaking Wave Impacts. Part 1: Results from Large-Scale Regular Wave Tests on Vertical and Sloping Walls." Coastal Engineering 54: 602-617. doi:10.1016/j.coastaleng.2006.12.002.

$\mathrm{CCH}$. 2000. City and County of Honolulu Building Code $(\mathrm{CCH})$. Department of Planning and Permitting of Honolulu Hawaii, Chapter 16, Article 11

Chanson, H.. 2004. The Hydraulics Of Open Channel Flow: An Introduction. 2nd ed. Oxford, UK: Elsevier.

Chanson, H. 2006. "Tsunami Surges on Dry Coastal Plains: Application of Dam Break Wave Equations." Coastal Engineering Journal 48 (4): 355-370. doi:10.1142/ S0578563406001477.

Chanson, H., S. Aoki, and M. Maruyama. 2000. "Experimental Investigation of Wave Run-Up Downstream of Nappe Impact; Application to Flood Wave Resulting from Dam Overtopping and Tsunami Wave Run-Up." Coastal/Ocean Engineering Report No. COEO0-2, Toyohashi University of Technology, Japan, 38 .

Chanson, H., S. Aoki, and M. Maruyama. 2002. "An Experimental Study of Tsunami Run-Up on Dry and Wet Horizontal Coastlines." International Journal of the Tsunami Society, Science of Tsunami Hazards 20 (5): 278-293.

Chinnarasri, C., N. Thanasisathit, A. Ruangrassamee, S. Weesakul, and P. Lukkunaprasit. 2013. "The Impact of Tsunami-Induced Bores on Buildings." Proceedings of ICE-Maritime Engineering 166 (1): 14-24. doi:10.1680/ maen.2010.31.

Chock, G. 2016. "Design for Tsunami Loads and Effects in the ASCE 7-16 Standard." Journal of Structural Engineering 142 (11): 04016093. doi:10.1061/(ASCE) ST.1943-541X.0001565.

Chock, G., I. Robertson, D. Kriebel, M. Francis, and I. Nistor. 2012. Tohoku Japan Tsunami of March 11, 2011 -
Performance of Structures, 348. American Society of Civil Engineers (ASCE).

Cross, R. 1967. "Tsunami Surge Forces." Journal of the Waterways and Harbors Division 93 (4): 201-231.

FEMA 55. 2000. Coastal Construction Manual. Washington DC, USA: Federal Emergency Management Agency.

Foster, A. S. J., T. Rossetto, and W. Allsop. 2017. "An Experimentally Validated Approach for Evaluating Tsunami Inundation Forces on Rectangular Buildings." Coastal Engineering 128: 44-57. doi:10.1016/j. coastaleng.2017.07.006.

Fritz, H. M., D. A. Phillips, A. Okayasu, T. Shimozono, H. Liu, F. Mohammed, V. Skanavis, C. E. Synolakis, and T. Takahashi. 2012. "The 2011 Japan Tsunami Current Velocity Measurements from Survivor Videos at Kesennuma Bay Using LiDAR." Geophysical Research Letters 39: 1-6. doi:10.1029/2011GL050686.

Fujima, K., F. Achmad, Y. Shigihara, and N. Mizutani. 2009. "Estimation of Tsunami Force Acting on Rectangular Structures." Journal of Disaster Research 4 (6): 404-409. doi:10.20965/jdr.2009.p0404.

Gupta, V. P., and S. C. Goyal. 1975. "Hydrodynamic Forces on Bridge Piers." Journal of the Institution of Engineers (India) 56: 12-16.

Jaffe, B. E., K. Goto, D. Sugawara, B. M. Richmond, S. Fujino, and Y. Nishimura. 2012. "Flow Speed Estimated by Inverse Modeling of Sandy Tsunami Deposits: Results from the 11 March 2011 Tsunami on the Coastal Plain near the Sendai Airport, Honshu, Japan." Sedimentary Geology 282: 90-109. doi:10.1016/j. sedgeo.2012.09.002.

Linton, D., R. Gupta, D. Cox, J. van de Lindt, M. E. Oshnack, and M. Clauson. 2013. "Evaluation of Tsunami Loads on Wood-Frame Walls at Full Scale." Journal of Structural Engineering 139 (8): 1318-1325. doi:10.1061/(ASCE) ST.1943-541X.0000644.

Lukkunaprasit, P., A. Ruangrassamee, and N. Thanasisathit. 2009. "Tsunami Loading on Buildings with Openings." Science of Tsunami Hazards 28 (5): 303.

Madsen, P., D. Fuhrman, and H. Schäffer. 2008. "On the Solitary Wave Paradigm for Tsunamis."." Journal of Geophysical Research: Oceans 113 (C12): 1978-2012. doi:10.1029/2008JC004932.

Meile, T., J. L. Boillat, and A. J. Schleiss. 2011. "Water-Surface Oscillations in Channels with Axi-Symmetric Cavities." Journal of Hydraulic. Research 49 (1): 73-81. doi:10.1080/ 00221686.2010 .534671$.

Mizutani, S., and F. Imamura. 2001. "Dynamic Wave Force of Tsunamis Acting on a Structure," Proceedings of the International Tsunami Symposium, 941-948, Seattle, USA, 7-9 August.

Morison, J. R., J. W. Johnson, and S. A. Schaaf. 1950. “The Force Exerted by Surface Waves on Piles." Journal of Petroleum Technology 2 (5): 149-154. doi:10.2118/950149-G.

Nistor, I., D. Palermo, Y. Nouri, T. Murty, and M. Saatcioglu. 2009. "Tsunami Forces on Structures." In Handbook of Coastal and Ocean Engineering Chapter 11, edited by K. Young, 261-286. Singapore: (UCLA), World Scientific.

Nouri, Y., I. Nistor, D. Palermo, and A. Cornett. 2010. "Experimental Investigation of Tsunami Impact on Free Standing Structures." Coastal Engineering Journal 52 (1): 43-70. doi:10.1142/S0578563410002117.

OCADI. 2009. "Technical Standards and Commentaries for Port and Harbour Facilities in Japan.", Overseas Coastal Area Development Institute of Japan, Ports and Harbours Bureau. Tokyo, Japan. 
Okada, T., T. Sugano, T. Ishikawa, T. Ohgi, S. Takai, and C. Hamabe. 2005. Structural Design Methods of Buildings for Tsunami Resistance (SMBTR). Japan: Building Center of Japan.

Qi, Z. X., I. Eames, and E. R. Johnson. 2014. "Force Acting on a Square Cylinder Fixed in a Free-Surface Channel Flow." Journal of Fluid Mechanics 756: 716-727. doi:10.1017/ jfm.2014.455.

Rahman, S., S. Akib, M. Khan, and S. Shirazi. 2014. "Experimental Study on Tsunami Risk Reduction on Coastal Building Fronted by Sea Wall." Scientific World Journal 7. http://dx.doi.org/10. 1155/2014/729357

Ramsden, J. D. 1996. "Forces on a Vertical Wall Due to Long Waves, Bores, and Dry-Bed Surges." Journal of Waterway, Port, Coastal and Ocean Engineering 122 (3): 134-141. doi:10.1061/(ASCE)0733-950X(1996)122:3(134).

Ritter, A. 1892. "Die Fortpflanzung Der Wasserwellen." Zeitschrift Verein Deutscher Ingenieure 36 (33): 947-954.

Robertson, I. N. 2016. "Tsunami Loads and Effects: Guide to the Tsunami Design Provisions of ASCE 7-16." In Asce. Reston, VA: ASCE (American Society of Civil Engineers) .

Robertson, I. N., K. Pacskowski, H. R. Riggs, and A. Mohamed. 2011. "Tsunami Bore Forces on Walls." 30th International Conference on Ocean, Offshore and Arctic Engineering: 395403.

Robertson, I. N., K. Pacskowski, H. R. Riggs, and A. Mohamed. 2013. "Experimental Investigation of Tsunami Bore Forces on Vertical Walls." Journal of Offshore Mechanics and Arctic Engineering 135 (2): 021601.1-8. doi:10.1115/ 1.4023149 .

Rossetto, T., W. Allsop, I. Charvet, and D. Robinson. 2011. "Physical Modelling of Tsunami Using a New Pneumatic Wave Generator." Coastal Engineering 58 (6): 17-527. doi:10.1016/j.coastaleng.2011.01.012.
Santo, J., and I. N. Robertson. 2010. Lateral Loading on Vertical Structural Elements Due to a Tsunami Bore, 64. Honolulu: University of Hawaii.

Shafiei, S., B. W. Melville, and A. Y. Shamseldin. 2016. "Experimental Investigation of Tsunami Bore Impact Force and Pressure on a Square Prism." Coastal Engineering 110: 1-16. doi:10.1016/j.coastaleng.2015.12.006.

Stoker, J. J. 1957. "Water Waves: The Mathematical Theory with Applications." Intersciences. New York, 567 pages.

Tokyo University and BRI. 2011. Interim Report of the Building Standards Improvement Promotion Project No. 40, A Study of Improvement of Building Standards etc in the Tsunami Critical Areas

Wüthrich, D., M. Pfister, and A. J. Schleiss. 2016. "Example of Wave Impact on a Residential House," Proceedings of the 4th IAHR Europe Congress, Liege, Belgium, 27-29 July 2016.

Wüthrich, D., M. Pfister, I. Nistor, and A. J. Schleiss. 2018. "Experimental Study of Tsunami-Like Waves on Dry and Wet Bed Generated with a Vertical Release Technique." Journal of Waterway, Port, Coastal and Ocean Engineering 144 (4): 04018006. doi:10.1061/(ASCE) WW.1943-5460.0000447.

Yeh, H. 2007. "Design Tsunami Forces for Onshore Structures." Journal of Disaster Research 2 (6): 531-536. doi:10.20965/jdr.2007.p0531.

Yeh, H., I. Robertson, and J. Preuss. 2005. Development of Design Guidelines for Structures that Serve as Tsunami Vertical Evacuation Sites. Vol. 4. Washington State Department of Natural Resources, Division of Geology and Earth Resources. Olympia, WA.

Yeh, H., P. Liu, and C. Synolakis. 1996. Long-Wave Run-Up Models, 403. Singapore: World Scientific . 